\title{
New Isolates of Sweet potato feathery mottle virus and Sweet potato virus C: Biological and Molecular Properties, and Recombination Analysis Based on Complete Genomes
}

Solomon Maina, School of Agriculture and Environment and the University of Western Australia (UWA) Institute of Agriculture, Faculty of Science, UWA, Crawley, WA 6009, Australia; and Cooperative Research Centre for Plant Biosecurity, Canberra, ACT 2617, Australia; Martin J. Barbetti, School of Agriculture and Environment and UWA Institute of Agriculture, Faculty of Science, UWA; Darren P. Martin, Institute of Infectious Diseases and Molecular Medicine, Computational Biology Group, University of Cape Town, Cape Town 7549, South Africa; Owain R. Edwards, CSIRO Land and Water, Floreat Park, WA 6014, Australia; and Cooperative Research Centre for Plant Biosecurity, Canberra, ACT 2617, Australia; and Roger A. C. Jones, ${ }^{\dagger}$ Department of Primary Industries and Rural Development, South Perth, WA 6151, Australia; UWA Institute of Agriculture, Faculty of Science, UWA

\begin{abstract}
Sweet potato feathery mottle virus (SPFMV) and Sweet potato virus $C$ (SPVC) isolates were obtained from sweetpotato shoot or tuberous root samples from three widely separated locations in Australia's tropical north (Cairns, Darwin, and Kununurra). The samples were planted in the glasshouse and scions obtained from the plants were graft inoculated to Ipomoea setosa plants. Virus symptoms were recorded in the field in Kununurra and in glasshouse-grown sweetpotato and I. setosa plants. RNA extracts from I. setosa leaf samples were subjected to highthroughput sequencing. New complete SPFMV $(n=17)$ and SPVC $(n=6)$ genomic sequences were obtained and compared with 47 sequences from GenBank. Phylogenetic analysis revealed that the 17 new SPFMV genomes all fitted within either major phylogroup A, minor phylogroup II, formerly $\mathrm{O}$; or major phylogroup B, formerly RC. Major phylogroup A's minor phylogroup I, formerly EA, only appeared when recombinants were included. Numbers of SPVC genomes were insufficient to subdivide it into phylogroups. Within phylogroup A's minor phylogroup II, the closest genetic match between an Australian and a Southeast Asian SPFMV sequence was the $97.4 \%$ nucleotide identity with an East Timorese sequence. Recombination analysis of the 43 SPFMV and 27 SPVC sequences revealed evidence of 44 recombination events, 16 of which involved interspecies sequence transfers between SPFMV and SPVC and

28 intraspecies transfers, 17 in SPFMV and 11 in SPVC. Within SPFMV, 11 intraspecies recombination events were between different major phylogroups and 6 were between members of the same major phylogroup. Phylogenetic analysis accounting for the detected recombination events within SPFMV sequences yielded evidence of minor phylogroup II and phylogroup B but the five sequences from minor phylogroup I were distributed in two separate groups among the sequences of minor phylogroup II. For the SPVC sequences, phylogenetic analysis accounting for the detected recombination events revealed three major phylogroups (A, B, and C), with major phylogroup A being further subdivided into two minor phylogroups. Within the recombinant genomes of both viruses, their PI, NIa-Pro, NIb, and CP genes contained the highest numbers of recombination breakpoints. The high frequency of interspecies and interphylogroup recombination events reflects the widespread occurrence of mixed SPVC and SPFMV infections within sweetpotato plants. The prevalence of infection in northern Australian sweetpotato samples reinforces the need for improved virus testing in healthy sweetpotato stock programs. Furthermore, evidence of genetic connectivity between Australian and East Timorese SPFMV genomes emphasizes the need for improved biosecurity measures to protect against potentially damaging international virus movements.
\end{abstract}

Sweetpotato (Ipomoea batatas; family Convolvulaceae) is among the most important staple food crops in the world due to its ability to both withstand harsh climatic conditions and produce edible tuberous roots that grow well in poor soils (FAOSTAT 2017; Kays et al. 2005). Central America and the Andes of South America are its

${ }^{\dagger}$ Corresponding author: R. A. C. Jones; E-mail: roger.jones@agric.wa.gov.au

Funding: This study forms part of a Ph.D. project by S. Maina at the University of Western Australia (UWA). The Cooperative Research Centre for Plant Biosecurity (CRCs) (PBCRC61056) and UWA provided a Scholarship for International Research Fees (SIRF). Both organizations and the Commonwealth Scientific and Industrial Research Organisation (CSIRO) provided operating funds. UWA and the Department of Agriculture and Food Western Australia (DAFWA) both provided glasshouse and laboratory facilities for this research.

*The $\boldsymbol{e}$-Xtra logo stands for "electronic extra" and indicates that one supplementary figure and two supplementary tables are published online.

Accepted for publication 19 March 2018.

(c) 2018 The American Phytopathological Society centers of domestication but its cultivation subsequently spread throughout the tropical, subtropical, and Mediterranean climate regions of the world. In Australia, where it is grown in warmer parts of the continent, especially in the northern regions, sweetpotato is an important food crop. Sweetpotato is also widely grown throughout Southeast Asia and Oceania, including three of Australia's island neighbors: East Timor, Indonesia, and Papua New Guinea (PNG).

Globally, sweetpotato production is constrained by viral diseases. Sweet potato feathery mottle virus (SPFMV) (genus Potyvirus, family Potyviridae) is the most widespread sweetpotato-infecting virus worldwide (Clark et al. 2012; Karyeija et al. 1998; Kashif et al. 2012; Moyer and Salazar 1989; Rännäli et al. 2009; Tairo et al. 2005, 2006). SPFMV isolates have been classified into three groups: the East African (EA), Ordinary (O), and Russet Crack (RC) phylogroups (Kreuze et al. 2000; Moyer et al. 1980; Tairo et al. 2005). Subsequently, a neutral within-species phylogenetic nomenclature system was introduced that uses letters of the alphabet and Latinized numerals to avoid potentially misleading names based on biology or geography (Jones and Kehoe 2016). Maina et al. (2018b) used it for SPFMV, replacing phylogroups $\mathrm{O}$ and $\mathrm{EA}$ by major phylogroup A minor phylogroups I and II, and replacing phylogroup RC by major phylogroup B. The closely related Potyvirus sp. Sweet potato virus $C$ (SPVC; genus Potyvirus, family Potyviridae), is also found 
infecting sweetpotato worldwide (Clark et al. 2012; Tairo et al. 2005). Furthermore, SPFMV and SPVC are often present in mixed infection within the same sweetpotato plants (Kashif et al. 2012; Kwak et al. 2015; Maina et al. 2018b). Viruses in both species are transmitted nonpersistently by aphids, by vegetative propagation, or both (Clark et al. 2012; Loebenstein et al. 2009).

Previous studies discovered SPVC and SPFMV major phylogroup A's minor phylogroup $\mathrm{O}(\mathrm{II})$ and major phylogroup $\mathrm{B}(\mathrm{RC})$ isolates infecting sweetpotato in North and South America, Europe, Australasia, Oceania, Africa, and Asia (Clark et al. 2012; EPPO 2014; Ha et al. 2008; Jones and Dwyer 2007; Maina et al. 2016c,d, 2018b; Rännäli et al. 2009; Tairo et al. 2005, 2006; Untiveros et al. 2008; Valverde et al. 2007). Although the EA(I) phylogroup was first found infecting sweetpotato in East Africa (Kreuze et al. 2000; Mukasa et al. 2003; Tairo et al. 2005), it is now known to also occur on other continents, including Spain in Europe, Peru in South America, Easter Island in Oceania, and both East Timor and Vietnam in Southeast Asia (Ha et al. 2008; Maina et al. 2018b; Rännäli et al. 2009; Untiveros et al. 2008; Valverde et al. 2004). SPFMV infects sweetpotato in East Timor, Indonesia, and PNG (Atkey and Brunt 1987; Coleman 2009; Maina et al. 2018b; Prain et al. 1998; Purnomo 2003). Although SPVC occurs in East Timor (Maina 2018a), whether it occurs in PNG or Indonesia is unknown.
In Southeast Asia, agriculture commenced more than 8,000 years ago (Hutterer 1983), and about 7,000 years ago in New Guinea (Denham et al. 2004). By contrast, in Australia, it has only been practiced since European colonization in 1788. Therefore, many viruses that pose threats to cultivated crops in other parts of the world are absent from Australia. Of the agriculturally important viruses present in Australia, many likely only arrived within the past century. Most of these recent introductions seem to have occurred through people unknowingly importing infected seed or vegetative plant materials (Gibbs et al. 2008; Jones 2009). However, from November to April every year, strong northwesterly monsoonal winds blow toward northern Australia from East Timor and Indonesia. These winds might also introduce viruliferous insect vectors to the continent (Eagles et al. 2013; Maina et al. 2017a,b). Evidence of such transfers was provided by a study of Zucchini yellow mosaic virus (ZYMV; genus Potyvirus, family Potyviridae), which indicated that isolates from the Ord River Irrigation Area (ORIA) in the East Kimberley region of northwest Australia were most closely related to isolates from East Timor, Singapore, and Vietnam. In contrast, none of the isolates collected from Broome in the West Kimberley, Darwin in the Northern Territory (which is adjacent to the East Kimberley), or any other locations around Australia belonged to this phylogroup (Coutts et al. 2011; Maina et al. 2017a). "Genetic connectivity" is a biosecurity

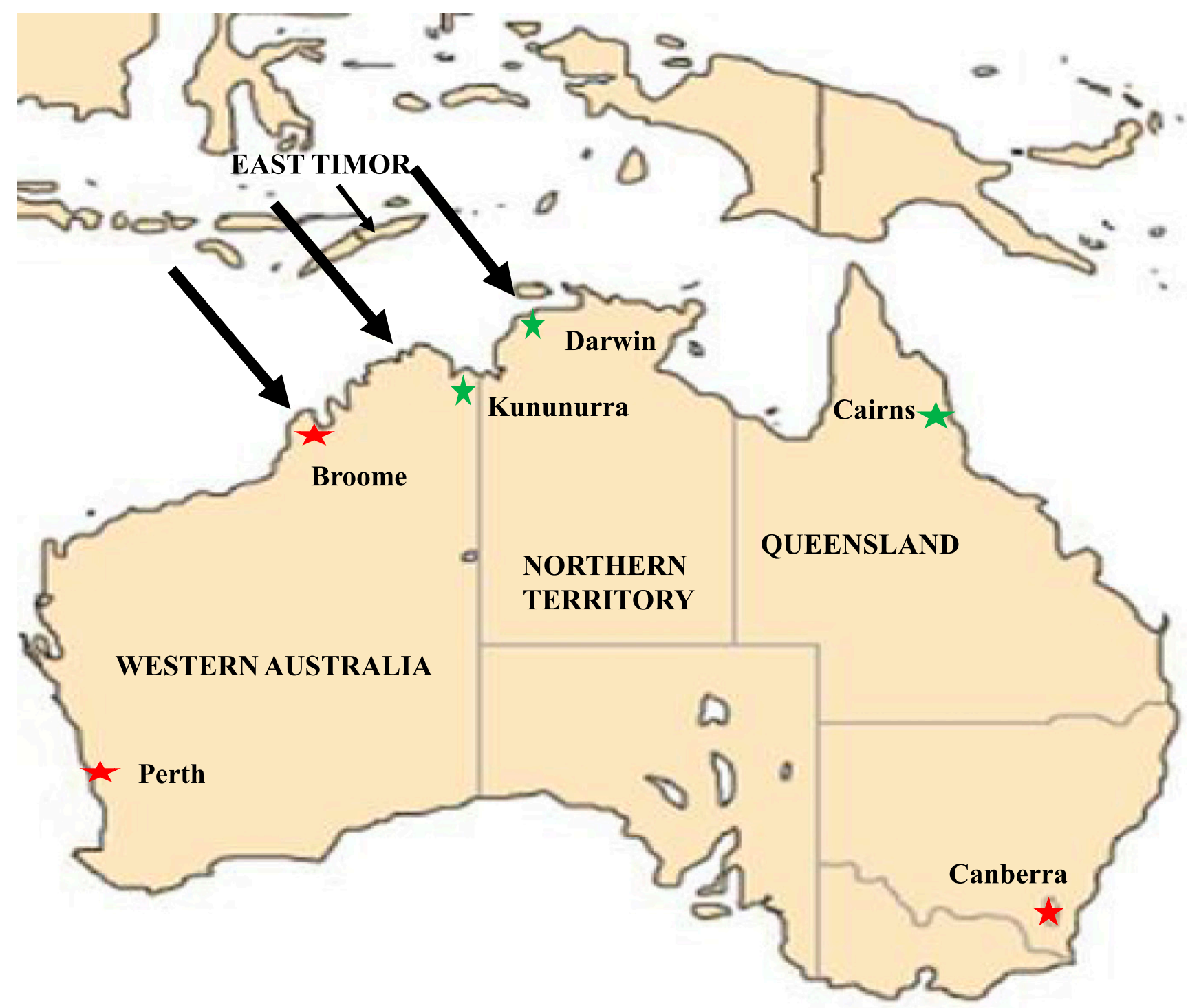

Fig. 1. Map showing locations where sweetpotato leaf samples infected with Sweet potato virus $C$ and Sweet potato feathery mottle virus were collected from sweetpotato plantings in the Australian mainland in this study or by Maina et al. (2018b) and the position of East Timor in relation to Australia. Arrows show annual November to April prevailing monsoonal wind direction. Green stars indicate sampling locations in far north Australia used in this study and red stars indicate sampling locations used by Maina et al. (2018b). 
term used to describe matching nucleotide sequence identities among samples derived from different countries and, in this regard, the ORIA ZYMV isolates displayed genetic connectivity with those from East Timor, Singapore, and Vietnam. Given that both SPFMV and SPVC are also both potyviruses transmitted nonpersistently by aphids (Clark et al. 2012; Loebenstein et al. 2009), it is plausible that either or both species might have reached Australia from Indonesia, PNG, or East Timor, either within viruliferous aphids blown by monsoonal winds or within imported cucurbit seed before stringent importation and quarantine measures were introduced.

Untiveros et al. (2008) conducted a recombination analysis using $3^{\prime}$ end 1,800-nucleotide (nt)-long sequences from 17 Potyvirus samples, most of which were SPFMV. They found recombinants in the $\mathrm{NIb}$ and coat protein $(\mathrm{CP})$ genes of SPFMV, the latter apparently involving a segment from SPVC. Tugume et al. (2010) undertook an extensive recombination study of partial SPFMV and SPVC sequences that compared isolates from different parts of the world, including isolates from wild host plants in East Africa in addition to sweetpotato. Their analysis involved CP (939 or $945 \mathrm{nt}$ ), NIb to $3^{\prime}$ untranslated region (UTR) sequences (approximately 1,800 nt), and 6KT to $3^{\prime}$ UTR (approximately 4,200 nt) sequences. They detected recombination frequently in the $6 \mathrm{~K} 2-\mathrm{VPg}-\mathrm{NIaPro}$ region of SPFMV minor phylogroup EA(I) but recombination between EA (I) and SPVC was rare. Yamasaki et al. (2010) obtained two complete genomes of SPFMV and one of SPVC which they compared with 12 partial sequences. One of these sequences was a recombinant in its P1 gene. Untiveros et al. (2010) obtained a genome of SPVC and compared it with one complete genome each of SPFMV minor phylogroups EA(I) and $\mathrm{O}(\mathrm{II})$ and major phylogroup B(RC). They found two recombination events in the genome of O(II). Kwak et al. (2015) obtained three complete genomes each of SPFMV and SPVC and compared them with four other complete genomes of SPFMV and three of SPVC. Apart from tentative recombination events supported by only one to three RDP4 program methods, they found two recombination events each supported by six to seven methods. These involved the NIa-Pro, CP NIb, and 3' UTR genes.
One isolate from minor phylogroup EA(I) had event parents from phylogroups $\mathrm{O}(\mathrm{II})$ and $\mathrm{B}(\mathrm{RC})$, whereas two isolates from phylogroup O(II) had different parents from O(II) and $\mathrm{B}(\mathrm{RC})$.

This article is part of a series arising from a plant biosecurity project testing the hypothesis that "important plant viral pathogens of economically important crops are arriving in tropical northern Australia by crossing the sea separating it from its northern island neighbors" (Maina and Jones 2017; Maina et al. 2016a,b,c,d,e,f, 2017a,b,c,d,e,f, 2018a,b). Although SPFMV and SPVC isolates from East Timor and Australia have been sequenced and complete coding regions are available in the National Center for Biotechnology Information (NCBI) database (Jones and Dwyer 2007; Maina et al. 2018b; Tairo et al. 2006), SPVC was considered to be an SPFMV phylogroup until it was recently reclassified as a separate species (Maina et al. 2018a,b; Tairo et al. 2005). Here, we describe virus symptoms that developed in SPFMV-infected and SPVC-infected sweetpotato plants from three widely separated locations in northern Australia. Shoot samples from these plants were graft inoculated to I. setosa plants, and 17 SPFMV and 6 SPVC genomes were sequenced from these plants. These genome sequences were used to investigate whether any genetic connectivity exists between the Australian SPFMV and SPVC populations and those of previously sequenced SPFMV and SPVC genomes from East Timor. Although this objective was addressed partially by Maina et al. (2018b), the current article addresses it more thoroughly because the new SPFMV and SPVC sequences described came from three other northern Australian locations (Cairns, Darwin, and Kununurra) which, when added to the previous single location in the northwest (Broome) from which SPFMV and SPVC sequences were obtained by Maina et al. (2018b), straddle the entire northern tropical region of the Australian continent. In addition, recombination analysis of 70 complete SPFMV or SPVC genomes was conducted using the latest version of the of the standard recombination detection program RDP5 version 2 to determine (i) whether ignoring recombination impacts the classification of phylogroups in these species and (ii) the occurrence of intraspecies and interspecies recombination.

Table 1. Details of the 18 virus-infected sweetpotato samples that provided complete genome sequences of the 17 Sweet potato feathery mottle virus (SPFMV) and 5 Sweet potato virus $C$ (SPVC) genomes sequenced ${ }^{\mathrm{a}}$

\begin{tabular}{|c|c|c|c|c|c|c|}
\hline Sample & Geographic origin in Australia & Year sampled & Sample origin, supplier & Isolate & Virus sequenced & Accession number \\
\hline $4 \mathrm{CA}$ & Cairns, QLD & 2016 & Richard Davis & Aus12A & SPVC & MG656433 \\
\hline $7 \mathrm{CA}$ & Cairns, QLD & 2016 & Richard Davis & Aus7CA & $\ldots{ }^{\mathrm{b}}$ & $\ldots$ \\
\hline $8 \mathrm{CA}$ & Cairns, QLD & 2016 & Richard Davis & Aus13D & SPFMV-B(RC) & MG656422 \\
\hline $13 \mathrm{CA}$ & Cairns, QLD & 2016 & Richard Davis & Aus14D & SPFMV-B(RC) & MG656425 \\
\hline $17 \mathrm{CA}$ & Cairns, QLD & 2016 & Richard Davis & Aus13A & SPVC & MG656435 \\
\hline $20 \mathrm{CA}$ & Cairns, QLD & 2016 & Richard Davis & Aus15D & SPFMV-B(RC) & MG656428 \\
\hline $20 \mathrm{CA}$ & Cairns, QLD & 2016 & Richard Davis & Aus14A & SPVC & MG656434 \\
\hline $21 \mathrm{CA}$ & Cairns, QLD & 2016 & Richard Davis & Aus16D & SPFMV-B(RC) & MG656429 \\
\hline $10 \mathrm{D}$ & Darwin, NT & 2016 & Jane Ray & Aus17D & SPFMV-B(RC) & MG656424 \\
\hline 11D & Darwin, NT & 2016 & Jane Ray & Aus14B & SPFMV-A-O(II) & MG656431 \\
\hline $2 \mathrm{~B}$ & Kununurra, WA & 2015 & This study & Aus15B & SPFMV-A-O(II) & MG656415 \\
\hline $2 \mathrm{BC}$ & Kununurra, WA & 2015 & This study & Aus16B & SPFMV-A-O(II) & MG656416 \\
\hline $2 \mathrm{BC}$ & Kununurra, WA & 2015 & This study & Aus18D & SPFMV-B(RC) & MG656417 \\
\hline $3 \mathrm{~A}$ & Kununurra, WA & 2015 & This study & Aus19D & SPFMV-B(RC) & MG656418 \\
\hline $3 \mathrm{~B}$ & Kununurra, WA & 2015 & This study & Aus20D & SPFMV-B(RC) & MG656420 \\
\hline $3 \mathrm{~B}$ & Kununurra, WA & 2015 & This study & Aus17B & SPFMV-A-(II)O & MG656419 \\
\hline $3 \mathrm{~B}$ & Kununurra, WA & 2015 & This study & Aus15A & SPVC & MG656432 \\
\hline 7B & Kununurra, WA & 2015 & This study & Aus21D & SPFMV-B(RC) & MG656421 \\
\hline $9 B-2$ & Kununurra, WA & 2015 & This study & Aus22D & SPFMV-B(RC) & MG656423 \\
\hline $10 \mathrm{~A}$ & Kununurra, WA & 2015 & This study & Aus16A & SPVC & MG656437 \\
\hline 14B & Kununurra, WA & 2015 & This study & Aus14E & $\ldots$ & $\ldots$ \\
\hline 16B & Kununurra, WA & 2015 & This study & Aus23D & SPFMV-B(RC) & MG656426 \\
\hline $16 \mathrm{~B}$ & Kununurra, WA & 2015 & This study & Aus17A & SPVC & MG656436 \\
\hline 18B-1 & Kununurra, WA & 2015 & This study & Aus24D & SPFMV-B(RC) & MG656427 \\
\hline $24 \mathrm{~A}$ & Kununurra, WA & 2015 & This study & Aus25D & SPFMV-B(RC) & MG656430 \\
\hline
\end{tabular}

${ }^{a}$ For SPFMV, $\mathrm{A}$ and $\mathrm{B}(\mathrm{RC})$ are its major phylogroups and $\mathrm{O}(\mathrm{II})$ is a minor phylogroup. Partial SPFMV or SPVC sequences were obtained from two of the above samples and seven other samples: 1A and 14B with SPFMV-RC; 16B and 24B with SPFMV-O; and 2A, 7CA, 10B, 14B, and 24B with SPVC. Aus = Australia, $\mathrm{NT}=$ Northern Territory, WA $=$ Western Australia, $\mathrm{QLD}=$ Queensland, $\mathrm{RC}=$ russet crack, and $\mathrm{O}=$ ordinary .

${ }^{\mathrm{b}}$ Other viruses than SPFMV and SPVC were also found in and sequenced separately from these two samples. 


\section{Materials and Methods}

Sample collection. Sweetpotato samples $(n=77)$ were collected between July and August 2015 from the ORIA near Kununurra in the East Kimberley region, and in February 2016 from Cairns in Queensland and Darwin in the Northern Territory (Fig. 1). These samples consisted of 30 sweetpotato shoots collected from two commercial farms and a community garden in Kununurra, and 24 and 23 tuberous roots purchased from farmers' markets in Cairns and Darwin, respectively. Sweetpotato plants from the ORIA that exhibited foliage symptoms were noted before sampling. Cooler boxes were used to transport shoot samples to Perth in southwest Australia. The tuberous root samples from Cairns and Darwin were sent to Perth by post. Of a total of 77 sweetpotato samples collected from the three locations, 56 were selected for planting: 25 from Kununurra, 11 from Darwin, and 20 from Cairns. The 25 shoot samples were rooted and the 31 tuberous roots were planted in potting mix. The plants that grew from them were maintained in airconditioned insect-proof glasshouses at approximately $23^{\circ} \mathrm{C}$. Shoots from each plant were side grafted to I. setosa plants (one shoot per plant). Foliage symptoms in sweetpotato and graft-inoculated I. setosa plants were recorded weekly for up to 2 months. Because the cultivars were unknown, to distinguish the different sweetpotato types, records were made of morphological and color descriptors from the plants and their tuberous roots. Tuberous root characteristics (shape, and skin and flesh color) and foliage characteristics (leaf shape and leaf, petiole, and stem color) were used as primary and secondary descriptors, respectively.

RNA extraction and reverse-transcription polymerase chain reaction. Symptomatic leaf samples collected from $I$. setosa were subjected to total RNA extraction using a ZR Plant RNA MiniPrep kit (Zymo Research, Irvine, CA), according to the manufacturer's instructions. Crude RNA was treated with RNase-free DNase (Invitrogen, Carlsbad, CA) and quality control was performed as described previously (Guerret et al. 2017; Maina and Jones 2017; Maina et al. 2016a,b,c,d,e,f, 2017a,b,c,d,e,f, 2018a,b). GoTaq Green master mix (Promega Corp., Madison, WI) and generic Potyvirus LegPotyF and LegPotyR primers were used for reverse-transcription polymerase chain reaction (RT-PCR), as described by Webster (2008). Evidence of potyviruses was found in 35 of the samples tested.

High-throughput sequencing. The 35 samples showing evidence of potyvirus infection by RT-PCR were selected for library preparation. Libraries were prepared from 0.1 to $1 \mu \mathrm{g}$ of total RNA using the TruSeq stranded Total RNA Sample Preparation kit with Ribozero Plant (Illumina, San Diego, CA). This involved subjecting their total RNA to depletion of ribosomal RNA (rRNA) using rRNA removal plant mix, as described previously (Maina and Jones 2017; Maina et al. 2016a,b,c,d,e,f, 2017a,b,c,d,e,f, 2018a,b). RNA extracts were primed with random hexamers, and first-strand cDNA synthesis was done using a mixture of Superscript II and Actinomycin D to allow RNA-dependent synthesis and inhibit DNA-dependent synthesis, respectively. Second-strand cDNA synthesis was done using dUTP instead of dTTP to create stranded cDNA; then, the libraries were adenylated at the $3^{\prime}$ end. Set A and B adaptors containing the identifier sequences and flow cell binding sequences were ligated to both ends. The cDNA fragment was enriched by 15 cycles of PCR and quality control was as described by Maina and Jones (2017) and Maina et al. (2016a,b,c,d,e,f, 2017a,b,c,d,e,f, 2018a,b). Sequencing involved sending ready-stranded libraries to Macrogen Inc. (South Korea), where they were subjected to HiSeq 2500 sequencing using a TruSeq rapid SBS kit v 4 (Illumina), with $151 \mathrm{cy}-$ cles to generate paired-end reads in multiplexed sample batches.

Sequence analysis. RNA-seq reads were subjected to quality control using CLC Genomics Workbench 6.5 (CLCGW) (CLC Bio; Qiagen, Redwood City, CA) followed by de novo assembly, as described previously (Guerret et al. 2017; Kehoe et al. 2014a; Maina and Jones
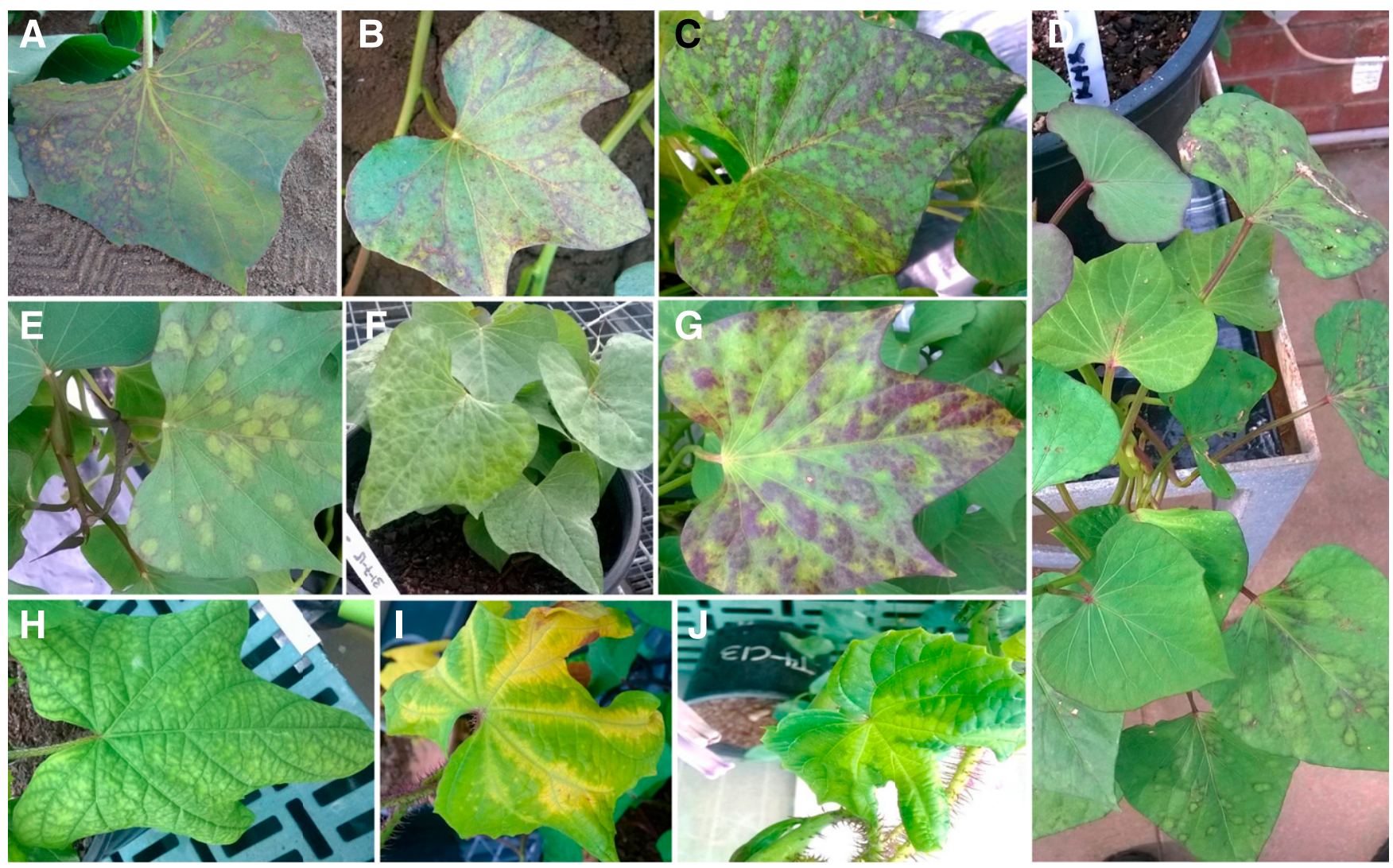

Fig. 2. Virus symptoms in $\mathbf{A}$ and $\mathbf{B}$, leaves of field-grown sweetpotato plants and $\mathbf{C}$ to $\mathbf{G}$, plants of glasshouse-grown sweetpotato or $\mathbf{H}$ to $\mathbf{J}$, graft-inoculated Ipomoea setosa. $\mathbf{A}$ and B, Purple rings caused by natural infection of leaves with different shapes from two plants of sweetpotato growing in 2015 in a commercial field at Kununurra, northwest Australia. C, Chlorotic blotches and purple rings; $\mathbf{D}$ and $\mathbf{E}$, faint purple rings surrounding individual or partially coalesced chlorotic blotches; $\mathbf{F}$, vein clearing, mild mosaic, and rugosity; $\mathbf{G}$, irregular purple and chlorotic blotches; $\mathrm{H}$, interveinal chlorosis; I, golden yellow vein banding and malformation; and J, pale green vein banding, mosaic and malformation. 
2017; Maina et al. 2016a,b,c,d,e,f, 2017a,b,c,d,e,f, 2018a,b). All of the assembled contigs were used as BLAST search queries with CLCGW and were then analyzed with the PASC sequence comparison tool (Altschul et al. 1990; Bao et al. 2014). All contigs with plant virus matches were carried forward for further analysis. In addition, trimmed reads from CLCGW were imported into Geneious 8.1.7 (Biomatters Ltd., Auckland, New Zealand) (Kearse et al. 2012) before mapping to a reference sequence from GenBank, as described by Kehoe et al. (2014a). Consensus sequence integrity was investigated and its full length determined with the contig of interest from CLCGW in Geneious by alignment with MAFFT (Katoh et al. 2002) to create a final sequence. SPFMV and SPVC genomes were fine-tuned by aligning nucleotide sequences to the deduced amino acid sequences using MUSCLE (Edgar 2004), available in Geneious. Geneious was also used both to predict open reading frames and annotate the genomes. Screening for vector contamination was done using the NCBI vector screen tool (https://www.ncbi. nlm.nih.gov/tools/vecscreen). Finalized sequences were obtained as complete coding sequences based on comparison with the reference sequences used in the mapping process. As found previously (Maina et al. 2018b), where virus sequences from sweetpotato differed in length, this was attributable to nucleotide insertion or deletions in the $5^{\prime}$ or $3^{\prime}$ UTR despite their complete polyprotein coding regions always being intact. Percent nucleotide (\% nt) identity scores between complete genomes were calculated using the pairwise function in Geneious with the number of differences model (Kearse et al. 2012), and a matrix of nucleotide identities produced using Sequence Demarcation tool v1 (Muhire et al. 2014). The 23 new full genome sequences were deposited in GenBank under the accession numbers MG656415 to MG656437 (Table 1).

Phylogenetic analysis. Using ClustalW in MEGA 7.0.14 (Kumar et al. 2016; Larkin et al. 2007), the 17 new SPFMV genome sequences were aligned with those of the 11 previously published Australian sequences (Maina et al. 2018a) and 15 other nonredundant genomic sequences from other parts of the world that are available in GenBank Similarly, the 6 new SPVC genomes were aligned with those of 11 previously published Australian SPVC sequences (Maina et al. 2018b) and the 10 other nonredundant genomic sequences from elsewhere in the world. Details of all of the complete SPFMV and SPVC sequences from GenBank and, where this is known, which phylogroups they belong to are provided in Supplementary Table $\mathrm{S} 1$. These GenBank sequences included ones from East Timor from Maina et al. (2018b) but none were available from Australia's northern neighbors Indonesia and PNG.

Further alignments were produced using MAFFT in Geneious (Katoh et al. 2002). Phylogenetic analysis compared (i) the coding regions of the 12 new SPFMV genome sequences from Australia with the 19 previously published complete SPFMV genomes ( 7 from Australia and 12 from elsewhere in the world), (ii) the coding regions of the 17 new complete SPFMV genome sequences from Australia with 26 previously published complete SPFMV genomes, and (iii) the combined coding regions of the 6 new complete SPVC genome sequences from Australia with 21 previously published SPVC genomes ( 7 from Australia and 14 from elsewhere in the world). Maximum-likelihood phylogenetic trees were constructed using the Tamura-Nei model (found to be the best fitting of eight tested models in MEGA 7.0.14) (Kumar et al. 2016), with bootstrap support values of 1,000. The codon positions included were first + second + third + noncoding. All ambiguous nucleotide positions were removed for each sequence pair. The SPFMV trees were rooted with SPVC IL (JX489166) and the SPVC trees with SPFMV-O 17-0 (AB509454). As was previously recommended by Jones and Kehoe (2016), two within-virus species phylogroup classification systems were used. The first is based on distinguishing biological characteristics or the region of the world where each isolate originated. The second uses a neutral nomenclature system involving letters of the alphabet and Latinized numerals that avoid potentially misleading names based on biology or geography.

Table 2. Details of 18 sweetpotato samples that provided complete virus genomes and 2 that provided three partial sequences: foliage symptoms in sweetpotato and Ipomoea setosa, distinguishing characteristics in progeny plants and tuberous roots, and viruses sequenced

\begin{tabular}{|c|c|c|c|c|c|c|c|c|c|}
\hline \multirow[b]{2}{*}{ Sample } & \multicolumn{3}{|c|}{ Foliage symptoms ${ }^{\mathbf{a}}$} & \multicolumn{2}{|c|}{ Morphology and color descriptors } & \multicolumn{4}{|c|}{ Virus detected $^{b}$} \\
\hline & Field & Glasshouse & I. setosa & Foliage $^{c}$ & Tuberous root $^{\mathrm{d}}$ & SPFMV & SPVC & CMV & SPVCV \\
\hline $4 \mathrm{CA}^{\mathrm{e}}$ & NA & CS & $\mathrm{M}, \mathrm{LDC}, \mathrm{VC}$ & GrL, GrP, GrSt, HsL & EL, GoBrSk, OrF & - & + & - & - \\
\hline $7 \mathrm{CA}^{\mathrm{e}}$ & NA & $\mathrm{CB}$ & LM, VB & $\mathrm{GrL}, \mathrm{GrP}, \mathrm{GrSt}, \mathrm{HsL}$ & EL, GoBrSk, OrF & $+\mathrm{P}$ & $+\mathrm{P}$ & $+\mathrm{P}$ & - \\
\hline $8 \mathrm{CA}^{\mathrm{e}}$ & NA & $\mathrm{C}$ & $\mathrm{C}, \mathrm{LM}, \mathrm{M}$ & GrL, GrP, GrSt, HsL & EL, GoBrSk, OrF & + & $\ldots$ & - & - \\
\hline $13 \mathrm{CA}^{\mathrm{e}}$ & NA & M & $\mathrm{M}, \mathrm{LM}, \mathrm{VC}$ & GrL, HsL, PuTiP, PuTiSt & Ov, PuSk, WCF & + & - & - & - \\
\hline $17 \mathrm{CA}^{\mathrm{e}}$ & NA & $\mathrm{C}$ & $\mathrm{C}, \mathrm{LM}, \mathrm{VC}$ & GrL, HsL, PuTiP, PuTiSt, & Ov, PuSk, WCF & - & + & - & - \\
\hline $20 \mathrm{CA}^{\mathrm{e}}$ & NA & $\mathrm{CS}$ & CS, LM & GrL, GrP, GrSt, HsL & EL, GoBrSk, OrF & + & + & - & - \\
\hline $21 C A^{e}$ & NA & $\mathrm{C}$ & $\mathrm{C}, \mathrm{M}, \mathrm{VC}$ & GrL, HsL, PuTiP, PuTiSt & Ov, PuSk, WCF & + & - & - & - \\
\hline $10 \mathrm{D}^{\mathrm{e}}$ & NA & M & $\mathrm{C}, \mathrm{M}, \mathrm{VB}$ & GrL, PoTriLoL, PuTiP, PuTiSt & EI, WhSk, WhF & + & - & - & - \\
\hline $11 \mathrm{D}^{\mathrm{e}}$ & NA & $\mathrm{CS}$ & $\mathrm{CS}, \mathrm{M}, \mathrm{VC}$ & GrL, GrP, HsL, PuTiSt & EI, GoBrSk, OrF & + & + & - & - \\
\hline $2 \mathrm{~B}$ & $\mathrm{C}$ & $\mathrm{CB}, \mathrm{Cr}, \mathrm{R}$ & $\mathrm{C}, \mathrm{M}, \mathrm{MM}$ & Grst, HsL, PuTiL, PuTiP & OvOb, GoBrSk, OrF & + & + & - & - \\
\hline $2 \mathrm{BC}$ & $\mathrm{C}$ & $\mathrm{CB}, \mathrm{Cr}$ & $\mathrm{C}, \mathrm{LM}, \mathrm{MM}$ & GrL, GrP, GrSt, HsL & EL, WSk, WhPuTiF & + & + & - & - \\
\hline $3 \mathrm{~A}$ & PuR & $\mathrm{CB}$ & $\mathrm{C}, \mathrm{LM}, \mathrm{M}, \mathrm{R}, \mathrm{VC}$ & GrL, GrP, GrSt, HsL & Ov, GoBrSk, OrF & + & - & - & - \\
\hline $3 \mathrm{~B}$ & PuR & $\mathrm{C}, \mathrm{PuR}$ & LM, MM & GrL, GrSt, PuTiP,TriLoL & EL, GoBrSk, OrF & + & + & - & - \\
\hline $7 \mathrm{~B}$ & $\mathrm{Cr}$ & M, PuRS & $\mathrm{LM}, \mathrm{M}, \mathrm{VC}$ & HsPoL, ReP, ReTiSt, ReTiL & Ov, GoBrSk, OrF & + & - & - & - \\
\hline $9 \mathrm{~B}-2$ & $\mathrm{Cr}$ & M & $\mathrm{C}, \mathrm{LM}, \mathrm{M}, \mathrm{VC}$ & GrL, GrP, HsL, ReSt & EL, GoBrSk, OrF & + & - & - & - \\
\hline $10 \mathrm{~A}$ & SS & PuR & $\mathrm{CB}, \mathrm{LM}, \mathrm{M}$ & HsL, PuTiL, PuTiP, PuTiSt & EL, GoBrSk, OrF & - & + & - & - \\
\hline $14 \mathrm{~B}$ & SS & SS & $\mathrm{M}, \mathrm{LM}, \mathrm{VC}$ & GrL, GrP, GrSt, HsL & EL, WSk, WhPuTiF & $+\mathrm{P}$ & $+\mathrm{P}$ & - & $+\mathrm{P}$ \\
\hline $16 \mathrm{~B}$ & M & M & $\mathrm{M}, \mathrm{LM}, \mathrm{VC}$ & PuTiL, ReP, RSt, TriLoL & EL, GoBrSk, OrF & + & + & - & - \\
\hline 18B-1 & $\mathrm{Cr}$ & SS & $\mathrm{M}, \mathrm{VC}$ & HsL, ReP, ReSt, ReTiL & EL, GoBrSk, OrF & + & - & - & - \\
\hline $24 \mathrm{~A}$ & M & $\mathrm{CB}, \mathrm{M}, \mathrm{PuR}$ & $\mathrm{CS}, \mathrm{LM}, \mathrm{M}, \mathrm{R}$ & GrP, Grst, GrL, PoTriLoL & OvOb, WhSk, WhPuTiF & + & - & - & - \\
\hline
\end{tabular}

a Foliage symptoms: $\mathrm{C}=$ chlorosis, $\mathrm{CB}=$ chlorotic blotches, $\mathrm{Cr}=$ crinkling, $\mathrm{CS}=$ chlorotic spots, $\mathrm{LM}=$ leaf malformation, $\mathrm{MM}=$ mild mosaic, $\mathrm{M}=$ mosaic, $\mathrm{LDC}=$ leaf down curling, $\mathrm{NA}=$ not applicable, $\mathrm{PuR}=$ purple rings, $\mathrm{PuRS}=$ purple ringspots, $\mathrm{R}=$ rugosity, $\mathrm{SS}=$ symptomless infection, $\mathrm{VB}=\mathrm{vein}$ banding, and $\mathrm{VC}=$ vein clearing.

${ }^{\mathrm{b}}$ Cucumber mosaic virus (CMV), Sweet potato feathery mottle virus (SPFMV), Sweet potato virus C (SPVC), and Sweet potato vein clearing virus (SPVCV); + indicates virus present, - indicates virus absent, and $\mathrm{P}$ indicates partial sequence.

${ }^{c}$ Foliage descriptors: $\mathrm{GrP}=$ green petioles, $\mathrm{GrL}=$ green leaves, $\mathrm{GrSt}=$ green stems, $\mathrm{HsL}=$ heart-shaped leaves, $\mathrm{HsPoL}=$ heart-shaped single pointed leaves, PoTriLoL $=$ pointed trilobed leaves, $\mathrm{PuTiP}=$ purple-tinged petioles, $\mathrm{PuTiSt}=$ purple-tinged stems, $\mathrm{ReP}=$ red petioles, $\mathrm{ReSt}=\mathrm{red}$ stems, ReTiSt $=$ red-tinged stem, ReTiL $=$ red-tinged leaves, and TriLoL $=$ pointed trilobed leaves.

d Tuberous root descriptors: $\mathrm{EL}=$ elongated shape, $\mathrm{GoBrSk}=$ golden-brown skin, $\mathrm{EI}=$ longated shape, $\mathrm{OrF}=$ orange flesh, $\mathrm{Ov}=\mathrm{oval}$ shape, $\mathrm{OvOb}=\mathrm{oval}-\mathrm{oblong}$ shape, $\mathrm{PuSk}=$ purple skin, $\mathrm{WCF}=$ white cream flesh, $\mathrm{WhSk}=$ white skin, $\mathrm{WhF}=$ white flesh, and $\mathrm{WhPuTiF}=$ white purple-tinged flesh.

e Tuberous root sample. 
Recombination detection. The complete coding sequences of the 17 new SPFMV genomes, the 6 new SPVC genomes from Australia, and 47 other previously published sequences retrieved from GenBank were assessed for evidence of recombination. RDP version 5.2 (Martin et al. 2015) was used to detect putative recombination breakpoints between these 70 sequences. Any detected recombination signals that were flagged by RDP5.2 as potentially arising through evolutionary processes other than recombination were disregarded. Default parameters were used for the seven recombination detection methods implemented in RDP5.2: RDP (Martin et al. 2005), GENECONV (Padidam et al. 1999), Bootscan (Martin et al. 2005), MaxChi (Smith 1992), Chimaera (Posada and Crandall
2001), 3Seq (Boni et al. 2007), and SiScan (Gibbs et al. 2000). Only potential recombination events with an associated Bonferronicorrected $P$ value $<0.05$ for four or more recombination detection methods were considered credible evidence of recombination (Ohshima et al. 2002). The BURT method was used to infer the locations and 95\% confidence intervals of breakpoint locations. Recombination breakpoint locations and the origins of regions of sequence that had potentially been transferred during recombination were verified individually using the phylogenetic tools implemented in RDP5.2. A maximum-likelihood phylogenetic tree accounting for recombination was constructed using RAxML (Martin et al. 2015) with the GTR-CAT model and 100 bootstrap replicates.

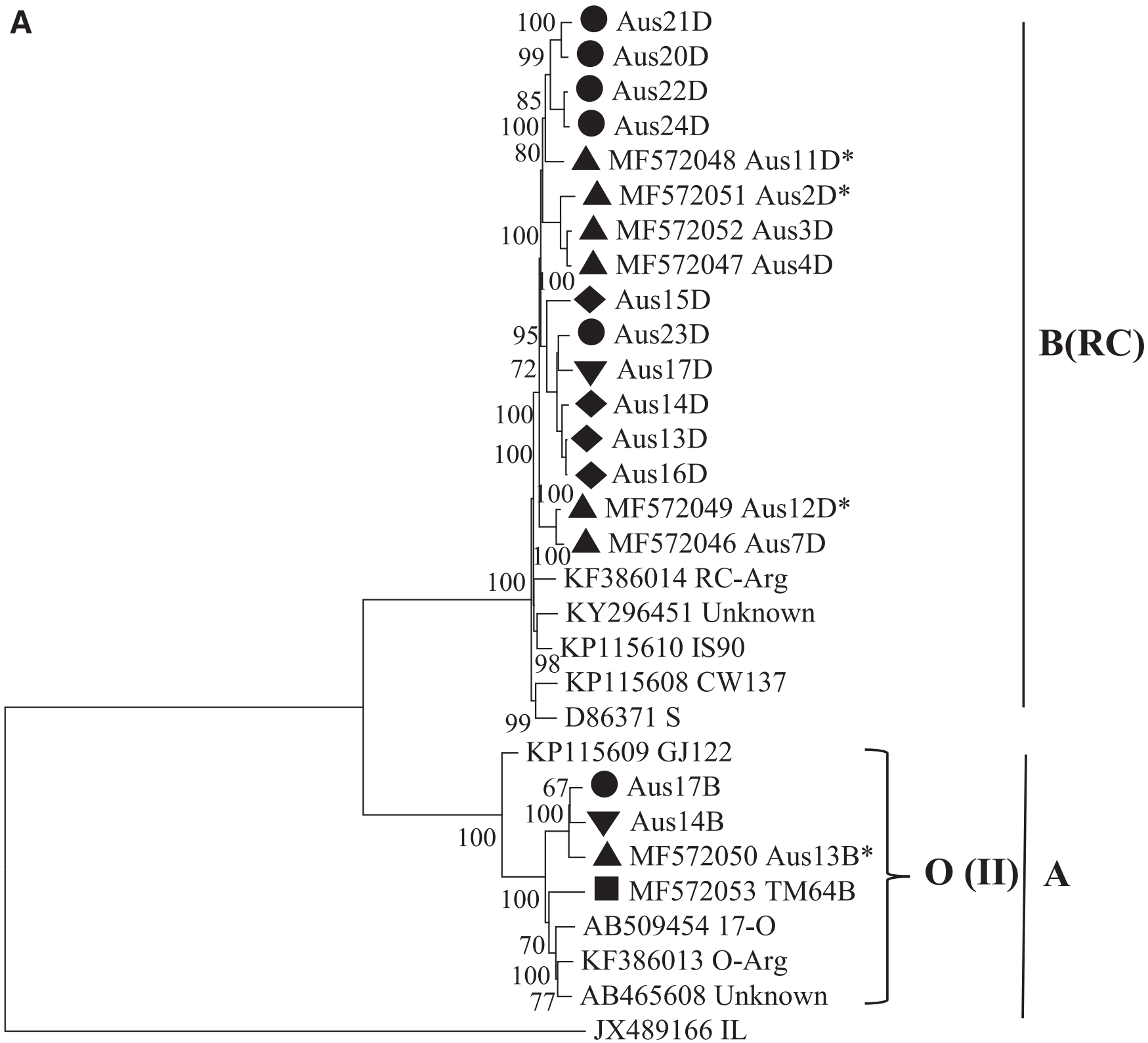

0.05

(Continued)

Fig. 3. Maximum-likelihood phylogenetic tree obtained from alignment of sequences of complete nucleotide sequences of Sweet potato feathery mottle virus. Comparisons made were between $\mathbf{A}$, the following nonrecombinant sequences: 12 new and 8 previously published Australian and East Timorese genome sequences, and 9 other genomic sequences from elsewhere obtained from GenBank; and B, the following nonrecombinant and recombinant sequences: 17 new and 11 previously published Australian and East Timorese genome sequences, and 15 other genome sequences from elsewhere obtained from GenBank. Trees were created in MEGA 7.0.14 using Clustal with 1,000 replicates. Bootstrap values are percentages with only values over $50 \%$ shown at the nodes. Trees were rooted with Sweet potato virus C IL (JX489166). Symbols: new Kununurra ( $)$, new Cairns ( $\bullet$ ), and new Darwin $(\boldsymbol{\nabla})$; and previously published Australian sequences $(\boldsymbol{\Delta})$, and East Timorese sequences $(\boldsymbol{\nabla})$. With the previous Australian sequences $(\boldsymbol{\Delta})$, those from Broome lack an extra symbol but those from Canberra and the Perth region are distinguished by an asterisk ( $\left.{ }^{*}\right)$. 


\section{Results}

Symptoms in sweetpotato and $I$. setosa plants. Of the 30 new shoot samples collected in the field in Kununurra in 2015, 27 were from symptomatic sweetpotato plants. Symptoms on the leaves of the three symptomatic plants consisted of chlorosis, chlorotic blotches, mosaic, purple rings, or crinkling (Fig. 2; Table 2). None of the tuberous root samples from Cairns and Darwin showed russet crack symptoms. When all of the 56 shoot and tuberous root sweetpotato samples were planted in the glasshouse, 29 of the plants that grew from them developed leaf symptoms: 20 from Kununurra, 7 from Cairns, and 2 from Darwin. These symptoms consisted of crinkling, chlorotic spots or blotches, purple rings or ringspots, mosaic, rugosity, or chlorosis. Each symptomatic plant exhibited between one and three of these different symptom types (Fig. 2; Table 2). Among the 56 graftinoculated $I$. setosa plants, 41 developed symptoms typical of virus infection: 26 from Kununurra, 10 from, Cairns and 5 from Darwin. Symptoms on the leaves of these plants consisted of leaf vein clearing, vein banding, chlorotic spots, mosaic, malformation, down curling,

Fig. 3. (Continued from previous page)

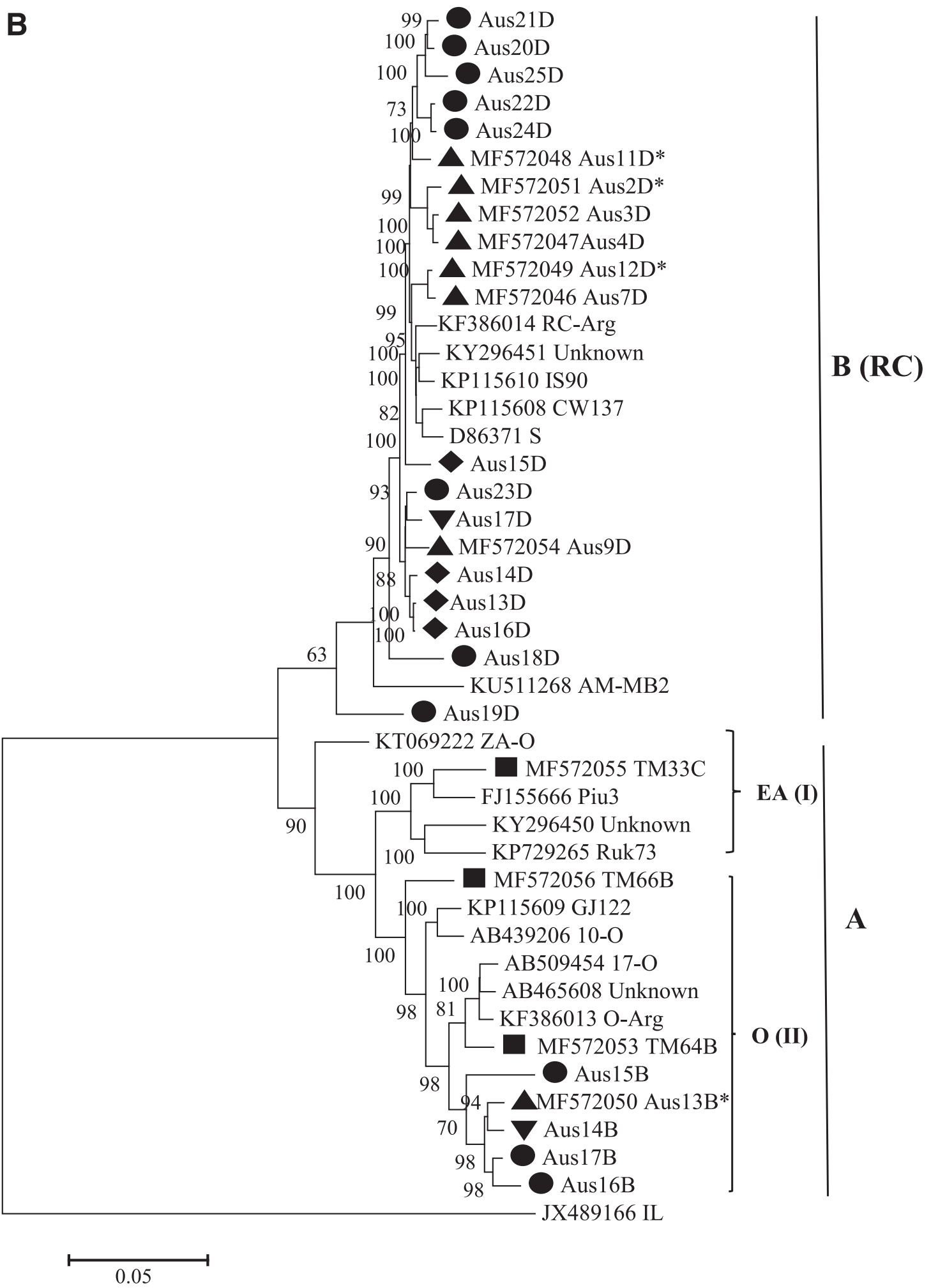


and chlorosis. Each symptomatic plant exhibited between two and five of these different symptom types (Fig. 2; Table 2).

Sweetpotato characterization. Among the sweetpotato plants from which complete or partial virus genomes were obtained, we identified seven different plant categories (Table 2): (i) tuberous roots that were elongated, white skinned, and white-purple-tinged fleshed, and had foliage consisting of heart-shaped, green leaves with green petioles and stems (two samples); (ii) tuberous roots that were elongated, white skinned, and white fleshed, and had foliage consisting of pointed trilobed, green leaves, and purple-tinged petioles and stems (one sample); (iii) tuberous roots that were elongated, golden-brown skinned, and orange fleshed, and had foliage consisting of heartshaped, green leaves with green petioles and stems (four samples), heart-shaped, red-tinged leaves with red petioles and stems (one sample), heart-shaped green leaves with green petioles and red stems (one sample), heart-shaped green leaves with green petioles and purpletinged stems (one sample), heart-shaped, purple-tinged leaves with purple-tinged petioles and stems (one sample), trilobed green leaves with purple-tinged petioles and green stems (one sample), or trilobed, purple-tinged leaves with red petioles and stems (one sample); (iv) tuberous roots that were elongated, purple skinned, and white-cream fleshed, and had foliage consisting of heart-shaped green leaves with purple-tinged petioles and stems (three samples); (v) tuberous roots that were oval, golden-brown skinned, and orange fleshed, and had foliage consisting of heart-shaped, green leaves with green petioles and stems, or heart-shaped, single-pointed, red-tinged leaves with red petioles and red-tinged stems (two samples); (vi) tuberous roots that were oval-oblong, golden-brown skinned, and orange fleshed, and had foliage consisting of heart-shaped, purple-tinged leaves, purple-tinged petioles, and green stems (one sample); and (vii) tuberous roots that were oval-oblong, white skinned, and purple-tinged fleshed, and had foliage consisting of pointed trilobed green leaves with green petioles and stems (one sample). No relationship was evident between the type of sweetpotato and either the symptoms that developed or the viruses that were subsequently detected within them (Table 2).

High-throughput sequencing. Analysis of the samples found that the numbers of raw paired-end reads obtained from HiSeq 2500 sequencing yielded between 8,501,492 and 26,938,692 but, after quality control, these numbers decreased to between $6,774,818$ and 23,840,584 (Supplementary Table S2). Following de novo assembly using CLCGW, the numbers of contigs were 50 to 3,652 and the number of reads mapping to the contigs of interest were 1,016 to $2,625,367$. The contigs of interest were more than $10,292 \mathrm{nt}$ in length, with average coverage of 10 to 24,519 . After mapping to reference genomes in Geneious, the lengths of the consensus sequences were 10,435 to $10,870 \mathrm{nt}$, with average coverage of 11 to 37,834 times. The numbers of reads mapped to the reference sequences were between 1,222 and 3,704,462. Final virus genome sequence lengths consisted of the consensus of the contig from CLCGW and the consensus from Geneious mapping, and were 10,540 to 10,930 nt. All of the sequenced samples had a Q30 of $>98 \%$ and yielded complete genomic sequences.

All of the contigs of interest belonged to SPFMV or SPVC. In addition to obtaining 17 SPFMV and 6 SPVC full genome sequences, 5 partial SPVC and 4 partial SPFMV genome sequences (2 SPFMVRC and 2 SPFMV-O) were also obtained from seven of the samples (Table 1). In addition, partial sequences of Cucumber mosaic virus (CMV; genus Cucumovirus, family Bromoviridae) and Sweetpotato vein clearing virus (SPVCV; genus Solendovirus, family Caulimoviridae) were found in samples Aus7CA and Aus14E, respectively (Tables 1 and 2).

Phylogenetic relationships. When the coding regions of the 12 new, complete nonrecombinant SPFMV genomes and 8 others reported previously from Australia or East Timor were compared with those of the 9 nonrecombinant SPFMV genomes from other continents, phylogenetic analysis revealed clustering into two major phylogroups (A and B) (Fig. 3A). Major phylogroup A contained previously named minor phylogroup $\mathrm{O}$ (II) but minor phylogroup EA(I) was absent. Within phylogroup O(II), the new Australian sequences, Aus14B from Darwin and Aus17B from Kununurra, grouped closely with the previously determined sequences, Aus13B from Australia and TM64B from East Timor. Major phylogroup B consisted of previously named phylogroup $\mathrm{RC}$ which included a large group of Australian sequences, 6 of which were previously reported, and 10 new Australian SPFMV sequences: 5 from Kununurra, 4 from Cairns, and 1 from Darwin. When all 29 nonrecombinant and 14 recombinant genomic sequences were used, the same major phylogroups appeared in the phylogenetic tree but minor phylogroup EA(I) was also present (Fig. 3B). Minor phylogroup O(II) of phylogroup A contained three recombinant sequences from Australia (new sequences Aus15B and Aus16B from Kununurra and previous sequence Aus13B from Perth), along with two recombinant sequences (TM64 and TM66B from East Timor) and recombinant sequence 10-O from Japan. Five recombinant sequences clustered within minor phylogroup EA(I): one each from South Africa, Uganda, East Timor, China, and Peru. Within major phylogroup $\mathrm{B}$, there were two groups of Australian sequences separated by the same five nonrecombinant sequences from other continents also present in Figure 3A. The group containing 11 Australian sequences now also included the recombinant sequence 25D from Kununurra, whereas the group containing 10 Australian sequences now included new recombinant sequences Aus18D and 19D from Kununurra, previous sequence Aus9D from Broome, and AMMB2 from Spain.

When the coding regions of the 6 new Australian SPVC genomic sequences and 11 previous Australian sequences were compared with the 21 SPVC sequences from other countries, there were insufficient differences between them to define phylogroups (Fig. 4). The six new Australian sequences (three each from Cairns and Kununurra) and seven previous Australian sequences all grouped together along with a single South African sequence, ECK17 (KT060223). Three East Timorese sequences grouped with sequences from Israel $(n=1)$, Argentina $(n=1)$, and East Asia $(n=4)$. However, the East Timorese sequence TM68A formed a small grouping with sequences AM-MB2 (KU511269) from Spain and C1 (GU207597) from Peru. Including or removing the recombinant sequences appeared to have little impact on the phylogenetic clustering of nonrecombinant sequences.

Sequence identities. When the 29 complete nonrecombinant SPFMV coding regions were analyzed, the closest genetic matches between an Australian and a Southeast Asian sequence was between minor phylogroup $\mathrm{O}$ (II) sequences within major phylogroup $\mathrm{A}$, where sequence TM64 from East Timor and sequences Aus17B from Kununurra and Aus13B from the Perth shared 97.4\% nt identities (Fig. 5A). The closest genetic match between Australian and non-East Timorese sequences within this phylogroup was the $97.6 \%$ nt identity between Aus13B and KF386013 from Argentina and AB465608 from Japan. The closest genetic match between any two of the new Australian sequences was the $99.3 \%$ nt identity between Kununurra sequences Aus20D and Aus21D within major phylogroup $\mathrm{B}(\mathrm{RC})$. Also, within this phylogroup, there was a close match $(99.0 \%$ nt identity) between Aus17D from Darwin and Aus23D from Kununurra, and the closest genetic match between any two of the new Australian sequences was 98.9\% nt identity between Aus17D from Kununurra and Aus14B from Darwin. The closest genetic matches between any Australian sequence and sequences from elsewhere were also within major phylogroup $\mathrm{B}(\mathrm{RC})$, where Aus12D from the Perth had a nucleotide identity of $98.4 \%$ with RC-Arg (KF386014) from Argentina.

When the 27 complete SPVC coding regions from Australia and elsewhere in the world were analyzed, the closest genetic match between an Australian sequence and any Southeast Asian sequence was 94.2\% nt identity between Aus15A from Kununurra and TM68A from East Timor (Fig. 5B). The closest match between any two Australian sequences was the $99.9 \%$ nt identity between $13 \mathrm{~A}$ and $14 \mathrm{~A}$, both from Cairns. There was also a close match (98.7\% nt identity) between Aus16A from Kununurra and Aus8A from Broome. The closest match between outlier Australian sequence Aus6A from 
Broome and any of the new sequences was $96.2 \%$ nt identity with two sequences from Cairns, Aus13A and Aus14A. The closest genetic match between any Australian SPVC sequence and a sequence from another part of the world was $98.7 \%$ nt identity between Aus3A from Broome and ECK17 (KT069223) from South Africa.

Recombination. All 70 SPFMV and SPVC sequences were aligned together and analyzed for recombination. This revealed evidence of 44 recombination events, each supported by four or more of the methods implemented in RDP5.2 (Fig. 6; Table 3). Of these, 16 events were between parental sequences belonging to the two different virus species (i.e., they were interspecies recombination events), 17 events were between different SPFMV variants, and 10 events were between different SPVC variants (i.e., these latter events were intraspecies recombination events), 6 between SPVC and SPFMV major phylogroup A and 10 between SPVC and SPFMV major phylogroup $\mathrm{B}(\mathrm{RC})$. In all, 11 of the 17 SPFMV intraspecies recombination events detected were between sequences in major phylogroups $\mathrm{A}$ and $\mathrm{B}(\mathrm{RC})$, while the other 6 were between sequences within major phylogroup $\mathrm{A}$, none occurring within phylogroup $\mathrm{B}$ (RC). There were 11 intraspecies recombination events between sequences in SPVC. Within the recombinant genomes of both species, the P1, NIa-Pro, NIb, and CP genes contained most of the detected recombination breakpoints, whereas the HC-Pro, 6K1, 6K2, and $\mathrm{C} 1$ genes contained the fewest recombination breakpoints. In all, 5 of the 11 new SPFMV sequences from Kununurra but none of the

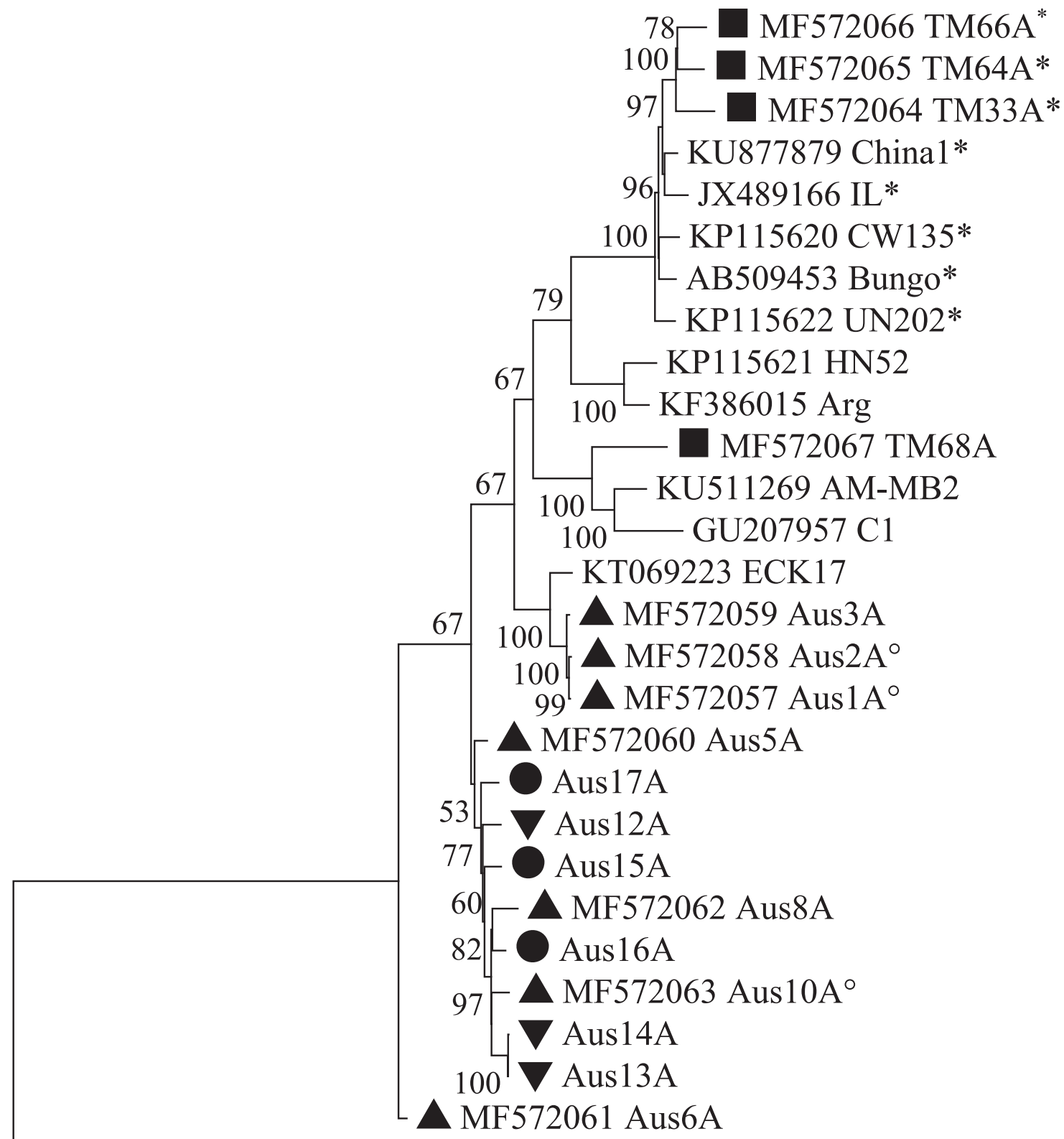

AB509454 17-0

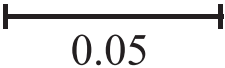

Fig. 4. Maximum-likelihood phylogenetic tree obtained from alignment of recombinant and nonrecombinant nucleotide genome sequences of Sweet potato virus $C$. The comparison made was between 6 new and the 11 previous Australian and East Timorese genome sequences, and 10 other genome sequences from elsewhere obtained from GenBank. The tree was created in MEGA 7.0.14 using Clustal W with 1,000 replicates. Bootstrap values are percentages with values over $50 \%$ shown at the nodes. The tree was rooted with Sweet potato feathery mottle virus 17-O (AB509454). Symbols: new Kununurra (O) and new Cairns ( $\boldsymbol{\nabla})$, previously published Australian ( $\mathbf{\Delta})$ and East Timorese sequences ( $\boldsymbol{\nabla})$, and recombinant sequences $\left({ }^{*}\right)$. With the previous Australian sequences $(\boldsymbol{\Delta})$, those from Broome lack an extra symbol but those from Canberra and Perth are distinguished by $\left({ }^{\circ}\right)$. 
new sequences from Darwin and Cairns were recombinants (Fig. 6; Table 3).

We constructed a maximum-likelihood phylogenetic tree using the SPFMV and SPVC alignment after removal of recombinationally derived tracts of sequence (Fig. 6). As mentioned above, the phylogenetic tree in Figure 3B exhibited two major SPFMV phylogroups (A and $\mathrm{B}$ ), A being subdivided into minor phylogroups EA(I) and O(II). In contrast, the tree in Figure 6 split the SPFMV sequences in major phylogroup $\mathrm{B}(\mathrm{RC})$ into two minor phylogroups: I and II. Minor phylogroup I contained 11 sequences, including a single recombinant which was one of the new Australian sequences, 25D from Kununurra. Minor phylogroup II contained 15 sequences, including 4 recombinants, 3 of which were the Australian sequences Aus18D and Aus19D from Kununurra and Aus9D from Broome. In major phylogroup A, 10 of the 17 sequences were identified as recombinants. These 10 sequences included all 5 of the sequences assigned in Figure 3B to minor phylogroup EA(I) and 5 sequences to minor phylogroup $\mathrm{O}$ (II). The five minor phylogroup $\mathrm{O}$ (II) recombinants detected in major phylogroup A included the new Australian sequences Aus15B and Aus16B from Kununurra, both with unique recombination patterns (Fig. 6). Also, two of the five recombinants from minor phylogroup EA(I) and one from minor phylogroup O(II) (TM66B [MF572056] from East Timor) grouped separately from the other nine minor phylogroup $\mathrm{O}$ (II) sequences and the other three minor phylogroup EA(I) sequences. The latter three sequences from phylogroup EA(I) (KP729265 from Uganda, KT069222 from South Africa, and KY296450 from China), all grouped together (Fig. 6) and all had different recombination patterns. By contrast, the other two phylogroup EA(I) sequences (FJ155666 from Peru and MF572055 from East Timor) each had the same recombination pattern. Overall, the 10 different recombinant sequences in major phylogroup A displayed several unique recombination patterns (Fig. 6) but fewer signals of recombination were detected in major phylogroup $\mathrm{B}$.

With minor phylogroup EA(I) sequences FJ155666 from Peru and MF572055 from East Timor, their parental sequences were major parent ZA-O (KT069222) and minor parent M66B (MF572056). Both of these sequences had different breakpoints, which were between nucleotides 7,708 and 9,448 for Piu3, affecting its NIa-Pro and NIb genes with a $P$ value of $7.292 \times 10^{-14}$, and between nucleotides 8,830 and 8,870 for TM33A, affecting its NIb gene with a $P$ value of $3.911 \times 10^{-21}$. Both events were detected by all seven of the recombination detection methods implemented in RDP5.2. Also, within the EA(I) phylogroup, the nucleotide sequence identities between ZA-O (KT069222) on the one hand and both TM33C (MF572055) and Piu3 (FJI55666) on the other hand were 90.4 and $90.9 \%$, respectively. However, rather than clustering with one of the other four sequences within phylogroup EA(I), the closest nucleotide identity to ZA-O was $94.1 \%$ nt identity with the phylogroup O(II) sequence GJ122 (KP1115609) from South Korea.

With SPVC, only one (Aus16A from Kununurra) of the new SPVC sequences was recombinant (Table 3; Fig. 6). However, unlike in the phylogenetic tree presented in Figure 4 (the tree based on the complete genomic sequences, ignoring the impact of recombination) (Table 3), in the phylogenetic tree in Figure 6 which accounts for

A KY296451
KP115610
KF386014
KP115608
D86371
MF572052
MF572047
MF572051
MF572049
MF572046
Aus21D
Aus20D
Aus22D
Aus24D
MF572048
Aus13D
Aus16D
Aus14D
Aus23D
Aus17D
Aus15D
MF572053
MF572050
Aus17B
Aus14B
KF386013
AB465608
AB509454
KP115609
KY296450
KP729265
JX489166

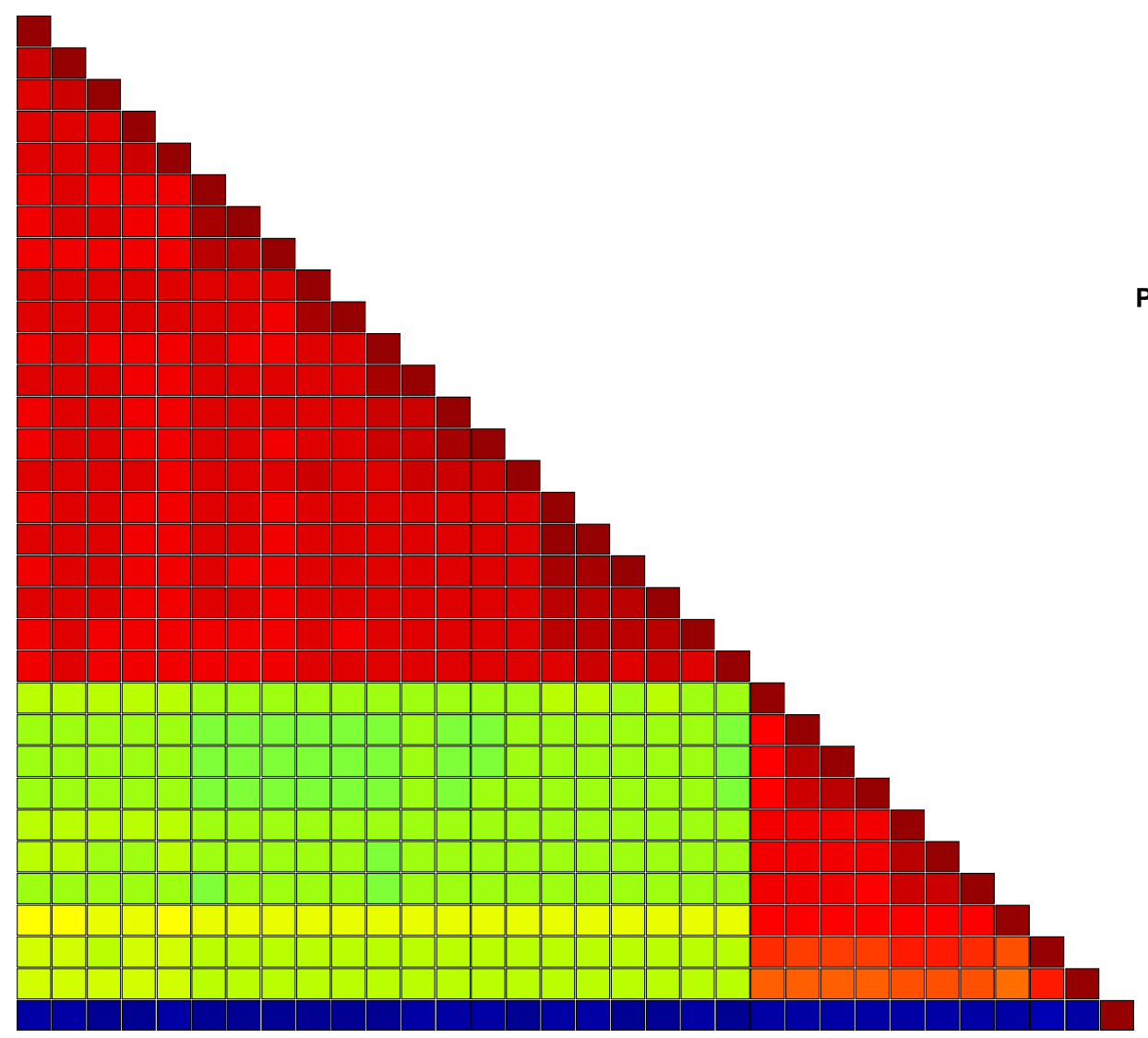

Pairwise identity (\%)
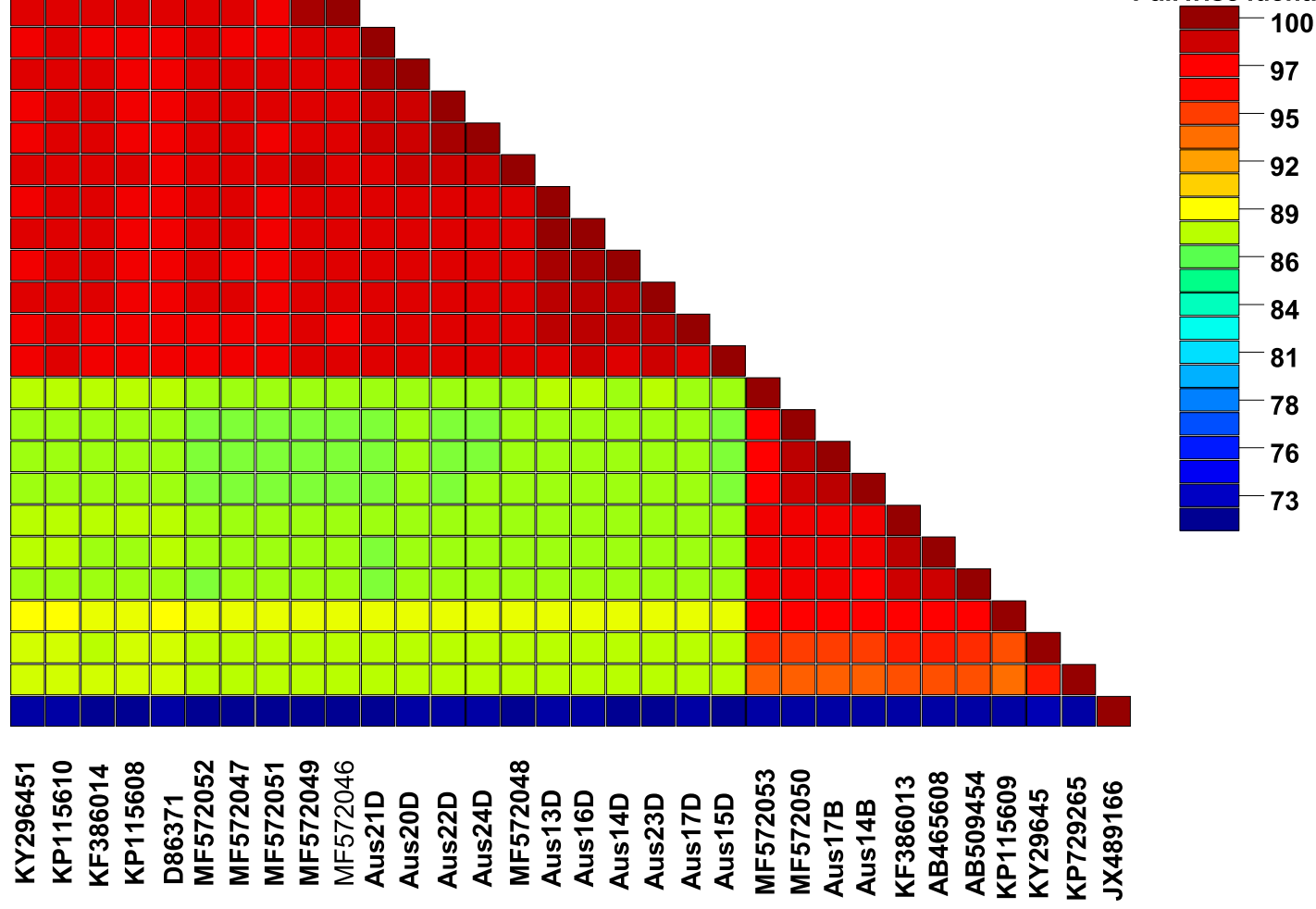

(Continued)

Fig. 5. Pairwise identity matrix generated from the A, 29 Sweet potato feathery mottle virus and B, 27 Sweet potato virus $C$ complete genomic sequences. Each colored key represents a percentage identity score between two sequences after alignments. 
recombination, there was evidence of distinct phylogroups. There were two major phylogroups (A and B), with major phylogroup A being subdivided into two minor phylogroups (I and II). Minor phylogroup I contained 10 sequences, 3 of which (including new sequence Aus16A) were recombinant, and included 5 other new nonrecombinant Australian sequences. Minor phylogroup II contained only four nonrecombinant sequences. Major phylogroup B contained 13 sequences, including 9 nonrecombinants and 4 recombinants, with 2 of the recombinants (KP115621 and KP115622, both from South Korea) exhibiting identical patterns of recombination.

\section{Discussion}

This study obtained the first complete SPFMV and SPVC genomic sequences from sweetpotato samples collected from three widely separated locations in the tropical far north of the Australian continent. Phylogenetic analyses of all genomes showed that these new Australian SPFMV genomes clustered together with other known Australian SPFMV sequences within major phylogroup B(RC) (13 new sequences) or major phylogroup A minor phylogroup O(II) (4 new sequences). Within phylogroup $\mathrm{O}(\mathrm{II})$, the close genetic match between a new Australian and an East Timorese sequence provided tentative evidence of genetic connectivity that could be explained by SPFMV having been introduced to northern Australia via viruliferous, windborne aphids from East Timor. With SPVC, analyses based on complete sequences found that the six new Australian SPVC genomes did not increase the known diversity of SPVC sufficiently to meaningfully subdivide this species into phylogroups. Our recombination analysis of 70 SPFMV and SPVC genomes identified which genome sequences were recombinants, determined the locations and sizes of recombinationally transferred genome fragments, and identified the sequences in the analyzed dataset that most closely resembled the parental sequences of recombinants. Within the recombinant genomes of both viruses, their PI, NiaPro, NIb, and CP genes contained the highest numbers of recombination breakpoints. There were interspecies recombination events between SPVC and SPFMV, intraspecies events within SPVC, and intraspecies recombination events within and between different SPFMV phylogroups. In the pursuit of recombination-free datasets, removing recombination-derived tracts of sequence from recombinant genomes prior to phylogenetic analysis rendered it unnecessary to discard other nucleotide data within recombinant genomes. Moreover, occurrence of recombination was apparently masking the presence of distinct SPVC phylogroups, because phylogroups became evident when recombination-derived tracts of sequence recombination were removed. Three major phylogroups (A, $\mathrm{B}$, and $\mathrm{C}$ ) then appeared, with major phylogroup A being further subdivided into two minor phylogroups. Another impact of recombination was the phylogenetic placement of sequences in minor SPFMV phylogroup EA(I) because, when recombination was not accounted for, its five sequences clustered together in a distinct phylogroup whereas, when it was accounted for, these sequences were distributed in two separate groups among the sequences of minor phylogroup O(II). As reported previously, our sequencing of samples and our recombination results revealed widespread occurrence of mixed infections between SPVC and SPFMV and involving different SPFMV phylogroups. However, evidence was lacking that any new SPFMV or SPVC introductions from overseas had arrived since the last Australian genomic sequences were obtained. There was also a lack of any clear association between viruses found and viral

Fig. 5. (Continued from previous page)
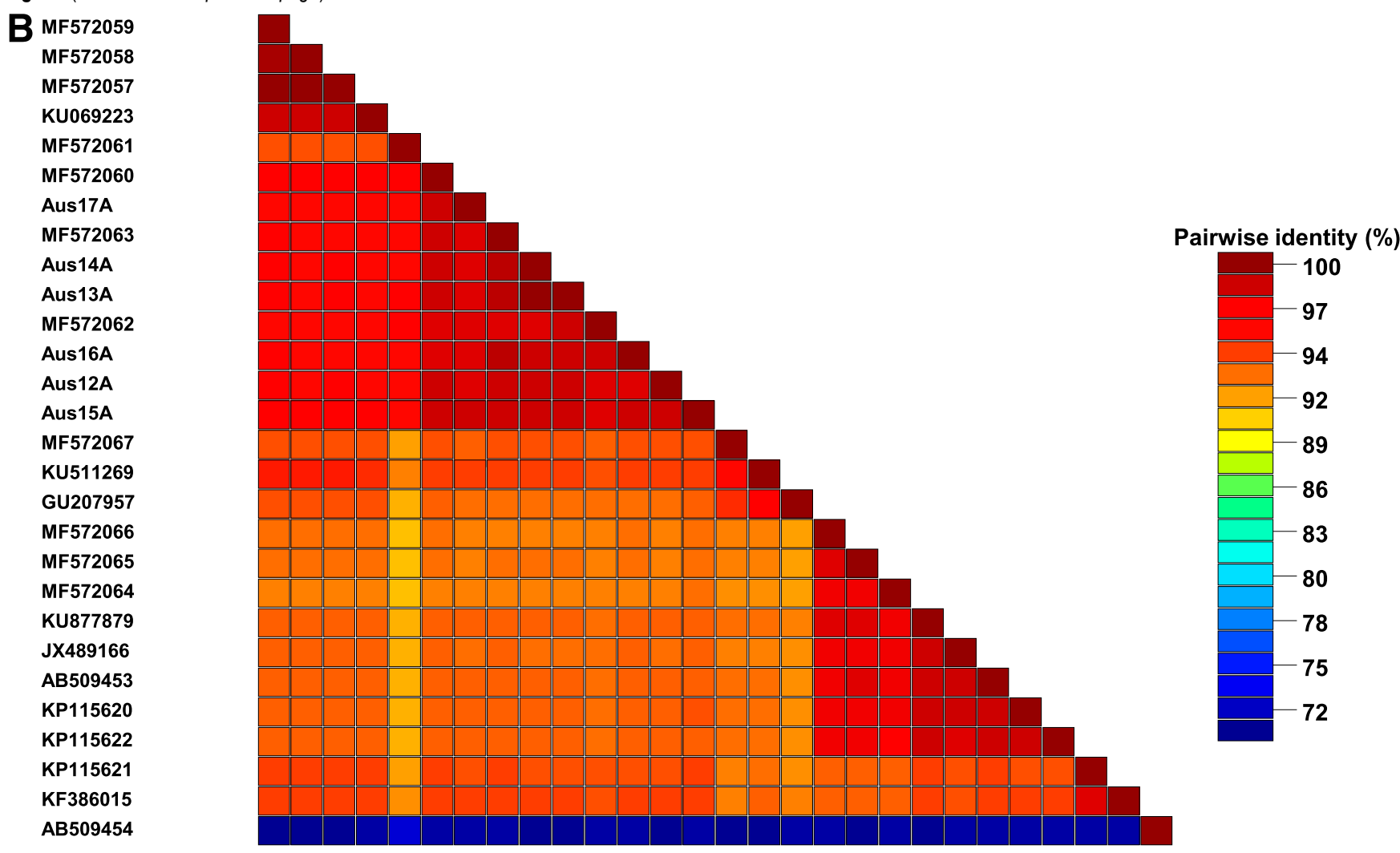
symptoms that developed in graft-inoculated I. setosa plants and field- or glasshouse-grown sweetpotato plants with different distinguishing characteristics.

SPFMV and SPVC are potyviruses that constitute a diverse genus of plant-infecting viruses with +sense RNA genomes. Both species readily produce mixed infections in sweetpotato plants and it is within such infections that genetic recombination must occur.
Recombination has been implicated in the rapid adaptation of viruses to new hosts and the development of increased virulence or pathogenicity (Chare and Holmes 2006; Gibbs and Ohshima 2010; Gibbs et al. 2008; James et al. 2016; Jones 2009; Kehoe et al. 2014b; Lai 1992; Maina et al. 2017a,b; Revers et al. 1996; Valli et al. 2007). Previous studies found strong evidence of recombination in various other potyviruses, with recombination breakpoints being detected most

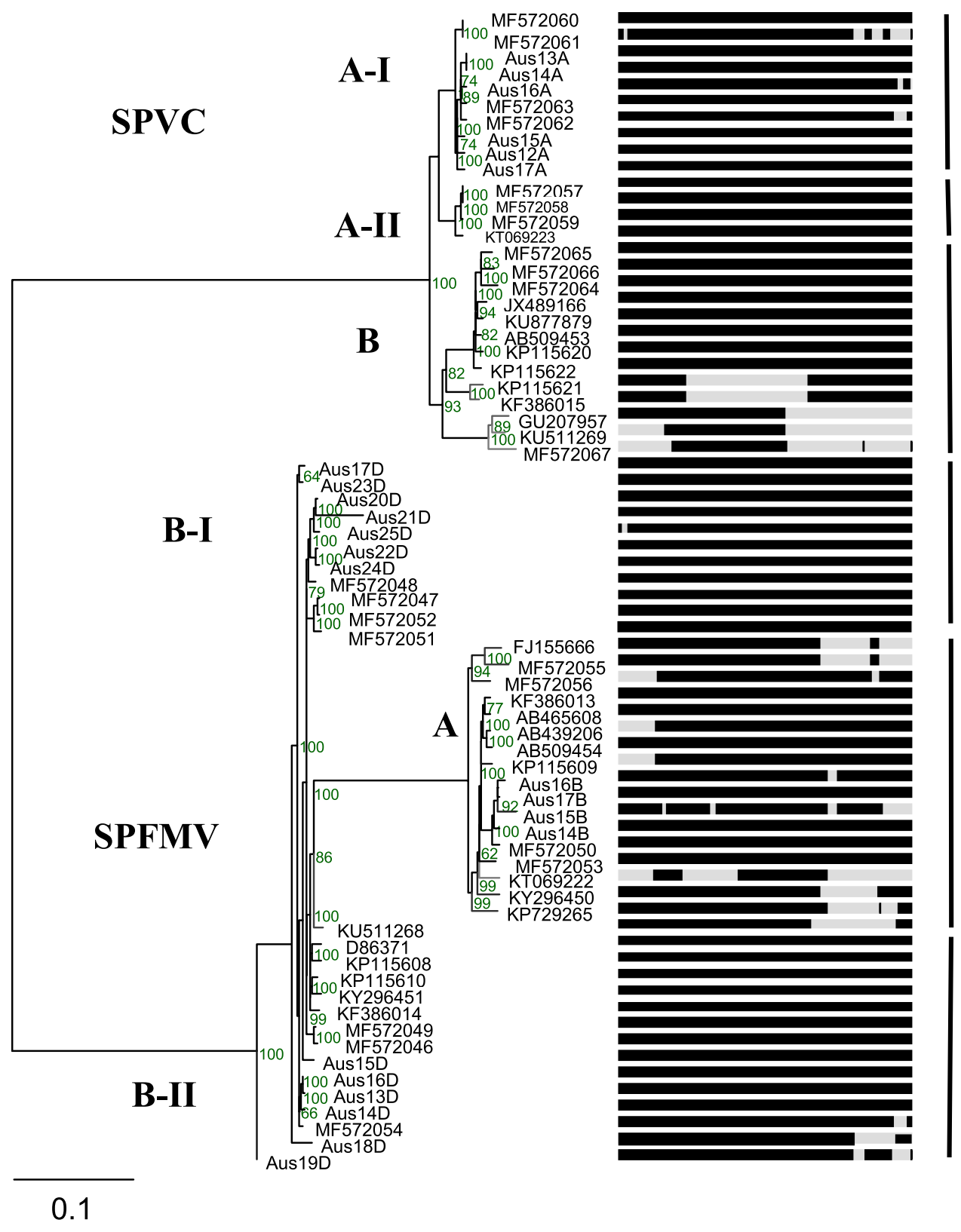

\section{Recombinant region}

\section{Non-recombinant region}

\section{Phylogroup border line}

Fig. 6. Maximum-likelihood phylogenetic tree obtained from alignment of nucleotide (nt) of 70 of Sweet potato feathery mottle virus (SPFMV) and Sweet potato virus C (SPVC) genomes with recombinant regions removed. The tree was inferred using PHYML/RAxML/FastTREE with 1,000 bootstrap test support, model GTR-CAT, and Faster RAxML tree search strategy in the RDP5.2 program. Gray line indicates recombinant region and black line indicates nonrecombinant region. 
frequently in the $\mathrm{P} 1, \mathrm{CI}$, and $\mathrm{Vpg}$ genes and less frequently in the CP gene (Desbiez and Lecoq 2008; Ohshima et al. 2007; Tan et al. 2004). By contrast, although our analysis of SPFMV and SPVC revealed a high frequency of recombination breakpoints within the P1 gene, similarly high numbers of breakpoints were found in the NIa-Pro, NIb, and CP genes. These genes are associated with genetic functions such as molecular amplification, pathogenicity, systemic movement, and symptom expression (Choi et al. 2013; James et al. 2016; Urcuqui-Inchima et al. 2001; Wen and Hajimorad 2010). The high frequency of intraspecies and interspecies recombination revealed that the recombination analysis performed here implicates recombination as a potential mechanism enabling SPFMV and SPVC to adapt to the different climatic conditions experienced and agricultural practices employed with sweetpotato cultivation in different parts of the world, and to the different kinds of alternative hosts for
SPFMV and SPVC present; for example, in the East African recombination hotspot for SPFMV evolution and diversification found by Tugume et al. (2010). Future studies could examine recombination frequencies in the different SPFMV phylogroups to provide more information about their adaptation to diverse environmental conditions and alternative host populations. Recombination presents a problem when it comes to inferring the evolutionary relationships of virus genomes, and its impacts on phylogenetic analyses are widely acknowledged (Chare and Holmes 2006; Myrta et al. 2001; Salminen 2003). However, recombination can be accounted for during phylogenetic and other evolutionary analyses by either excluding recombinant genomes, only analyzing regions of genomes where recombination breakpoints are absent, or removing recombinationally derived tracts of sequence from recombinant genomes prior to analysis (Chikh-Ali et al. 2016; Cuevas et al. 2012; Gibbs et al. 2017; Karasev

Table 3. Intra- and interspecies recombination events identified by the RDP5.2 package within the genomes of Sweet potato feathery mottle virus (SPFMV) and Sweet potato virus $C(\mathrm{SPVC})^{\mathrm{a}}$

\begin{tabular}{|c|c|c|c|c|c|c|c|c|}
\hline Event & $\begin{array}{l}\text { Virus and } \\
\text { phylogroup }\end{array}$ & Detected recombinant & $\begin{array}{c}\text { Detected } \\
\text { breakpoint } \\
\text { positions }\end{array}$ & $\begin{array}{c}\text { Genes } \\
\text { affected }\end{array}$ & Major parental sequences ${ }^{b}$ & Minor parental sequences $^{\mathbf{b}}$ & $\begin{array}{c}\text { Detected } \\
\text { methods } \\
\text { in RDP4 }\end{array}$ & Highest $P$ value \\
\hline $1^{\mathrm{d}}$ & SPFMV_A-O(II) & AB439206_10-O & $47-1,387$ & $5^{\prime}$ UTR, P1 & AB508454_SPFMV_A-O(I) & D86371_SPFMV_B(RC) & R,G,B,M,C,S,T & $9.883 \times 10^{-24}$ \\
\hline $2^{\mathrm{e}}$ & SPVC & MF572061_Aus6A & $1,032-10,357$ & $\mathrm{P} 1, \mathrm{CP}$ & MF572060_SPVC & MF572055_SPFMV_A-EA(I) & $\mathrm{R}, \mathrm{G}, \mathrm{B}, \mathrm{M}, \mathrm{C}, \mathrm{T}$ & $9.217 \times 10^{-10}$ \\
\hline $3^{f}$ & SPVC & MF572061_Aus6A & $8,946-9,358$ & $\mathrm{NIb}$ & MF572060_SPVC & Aus19D_SPFMV_B(RC) & G,B,M,C,S,T & $8.787 \times 10^{-18}$ \\
\hline $4^{f}$ & SPFMV_B(RC) & MF572054_Aus9D & $10,494-10,975$ & 3' UTR, CP & Aus13D_SPFMV_B(RC) & Aus12A_SPVC & $\mathrm{G}, \mathrm{B}, \mathrm{M}, \mathrm{C}, \mathrm{S}$ & $4.170 \times 10^{-18}$ \\
\hline $5^{e}$ & SPFMV_A-O(II) & Aus16B & $7,980-8,338$ & $\mathrm{NIb}$ & Aus17B_SPFMV_A-O(II) & MF572060_SPVC & $\mathrm{R}, \mathrm{G}, \mathrm{B}, \mathrm{M}, \mathrm{C}, \mathrm{S}$ & $4.828 \times 10^{-73}$ \\
\hline $6^{\mathrm{d}}$ & SPFMV_B(RC) & KU511268_AM-MB2 & $7,320-8,204$ & NIa-Pro, NIb & Aus18D_SPFMV_B(RC) & AB508454_SPFMV_A-O(II0 & $\mathrm{R}, \mathrm{G}, \mathrm{B}, \mathrm{M}, \mathrm{C}, \mathrm{S}, \mathrm{T}$ & $5.994 \times 10^{-22}$ \\
\hline $7^{f}$ & SPVC & MF572062_Aus8A & $10,482-10,958$ & 3' UTR, CP & Aus19D_SPFMV_B(RC) & MF572063_SPVC & $\mathrm{G}, \mathrm{B}, \mathrm{M}, \mathrm{C}, \mathrm{S}, \mathrm{T}$ & $9.321 \times 10^{-70}$ \\
\hline $8^{f}$ & SPVC & MF572061_Aus6A & $9,656-9,640$ & $\mathrm{CP}$ & Aus17A_SPVC & MF572054_SPFMV_B(RC) & $\mathrm{R}, \mathrm{G}, \mathrm{B}, \mathrm{M}, \mathrm{C}, \mathrm{S}$ & $8.878 \times 10^{-08}$ \\
\hline $9^{d}$ & SPFMV_A-O(II) & MF572056_TM66B & $1-1,452$ & $5^{\prime}$ UTR, P1 & Aus14B_SPFMV_A-O(II) & D86371_SPFMV_B(RC) & $\mathrm{R}, \mathrm{G}, \mathrm{B}, \mathrm{M}, \mathrm{C}, \mathrm{S}, \mathrm{T}$ & $8.926 \times 10^{-56}$ \\
\hline $10^{\mathrm{d}}$ & SPFMV_A-EA(I) & KT069222-_ZA-O & $2,476-4,536$ & HC-Pro & AB439206_SPFMV_A-O(II) & KF386014_SPFMV_B(RC) & $\mathrm{R}, \mathrm{G}, \mathrm{B}, \mathrm{M}, \mathrm{C}, \mathrm{S}, \mathrm{T}$ & $9.321 \times 10^{-69}$ \\
\hline $11^{\mathrm{d}}$ & SPFMV_B(RC) & KU511268-_AM-MB2 & $8,205-10,550$ & $\mathrm{NIb}, \mathrm{CP}$ & Aus18D_SPFMV_B(RC) & FJ155666_SPFMV_A-EA(I) & $\mathrm{R}, \mathrm{G}, \mathrm{B}, \mathrm{M}, \mathrm{C}, \mathrm{S}, \mathrm{T}$ & $6.284 \times 10^{-28}$ \\
\hline $12^{\mathrm{f}}$ & SPFMV_B(RC) & Aus19D & $8,932-9,358$ & $\mathrm{NIb}$ & Aus13D_SPFMV_B(RC) & MF572060_SPVC & $\mathrm{R}, \mathrm{G}, \mathrm{B}, \mathrm{M}, \mathrm{C}, \mathrm{S}$ & $9.010 \times 10^{-56}$ \\
\hline $13^{\mathrm{d}}$ & SPFMV_A-EA(I) & KT069222_ZA-O & $10-1,340$ & $5^{\prime}$ UTR, P1 & FJ155666_SPFMV_A-EA(I) & KF386014_SPFMV_B(RC) & $\mathrm{R}, \mathrm{G}, \mathrm{B}, \mathrm{M}, \mathrm{C}, \mathrm{S}, \mathrm{T}$ & $7.276 \times 10^{-28}$ \\
\hline $14^{\mathrm{f}}$ & SPFMV_B(RC) & Aus25D & $144-321$ & P1 & Aus20D_SPFMV_B(RC) & Aus15A_SPVC & $\mathrm{G}, \mathrm{B}, \mathrm{M}, \mathrm{C}$ & $5.2121 \times 10^{-44}$ \\
\hline $15^{\mathrm{d}}$ & SPFMV_A-O(II) & Aus15B & $10,070-10,531$ & $\mathrm{CP}$ & Aus17B_SPFMV_A-O(II) & Aus23D_SPFMV_B(RC) & $\mathrm{R}, \mathrm{G}, \mathrm{B}, \mathrm{M}, \mathrm{C}, \mathrm{S}, \mathrm{T}$ & $8.056 \times 10^{-38}$ \\
\hline $16^{\mathrm{f}}$ & SPVC & MF572061_Aus6A & $236-363$ & $\mathrm{P} 1$ & MF572060_SPVC & Aus20D_SPFMV_B(RC) & $\mathrm{G}, \mathrm{B}, \mathrm{M}, \mathrm{C}$ & $7.355 \times 10^{-43}$ \\
\hline $18^{\mathrm{e}}$ & SPFMV_A-O(II) & Aus15B & $1,656-1,818$ & P1 & Aus16B_SPFMV_A-O(II) & MF572061_SPVC & $\mathrm{G}, \mathrm{B}, \mathrm{M}, \mathrm{C}, \mathrm{S}$ & $7.979 \times 10^{-05}$ \\
\hline $19^{\mathrm{e}}$ & SPFMV_A-O(II) & Aus15B & $3,476-3,684$ & P3 & us16B_SPFMV_A-O(II) & MF572061_SPVC & $\mathrm{G}, \mathrm{B}, \mathrm{M}, \mathrm{C}, \mathrm{S}$ & $7.088 \times 10^{-07}$ \\
\hline $20^{g}$ & SPFMV_A-EA(I) & KT069222_ZA-O & $9,971-10,803$ & 3' UTR, CP & AB439206_SPFMV_A-O(II) & KP115608_SPFMV_A-O(II) & $\mathrm{R}, \mathrm{G}, \mathrm{B}, \mathrm{M}, \mathrm{C}, \mathrm{S}, \mathrm{T}$ & $2.326 \times 10^{-16}$ \\
\hline $21^{\mathrm{d}}$ & SPFMV_A-O(II) & Aus15B & $10,287-10,905$ & $3^{\prime} \mathrm{UTR}, \mathrm{CP}$ & Aus17B_SPFMV_A-O(II) & Aus20D_SPFMV_B(RC) & $\mathrm{R}, \mathrm{G}, \mathrm{B}, \mathrm{M}, \mathrm{C}, \mathrm{S}$ & $5.689 \times 10^{-06}$ \\
\hline $22^{\mathrm{h}}$ & SPVC & GU207957_C1 & $6,927-10,820$ & $\begin{array}{l}\text { 3' UTR, NIa-Pro, } \\
\text { VIb, NIb, CP }\end{array}$ & KF386015_SPVC & MF572057_SPVC & $\mathrm{R}, \mathrm{G}, \mathrm{B}, \mathrm{M}, \mathrm{C}, \mathrm{S}$ & $7.816 \times 10^{-13}$ \\
\hline $23^{\mathrm{g}}$ & SPFMV_A-EA(I) & KP729265_Ruk73 & $7,959-9,970$ & $\mathrm{VIb}, \mathrm{NIb}$ & AB4656608_SPFMV_A-O(II) & MF572055_SPFMV_A-EA(I) & $\mathrm{R}, \mathrm{G}, \mathrm{B}, \mathrm{M}, \mathrm{C}, \mathrm{S}, \mathrm{T}$ & $7.962 \times 10^{-18}$ \\
\hline $24^{g}$ & SPFMV_A-EA(I) & KY296450_Unknown & $7,731-9,650$ & VIb, NIb & AB4656608_SPFMV_A-O(II) & MF572055_SPFMV_A-EA(I) & $\mathrm{R}, \mathrm{G}, \mathrm{B}, \mathrm{M}, \mathrm{C}, \mathrm{S}, \mathrm{T}$ & $8.476 \times 10^{-16}$ \\
\hline $25^{\mathrm{h}}$ & SPVC & MF572067_TM68A & $9,402-10,683$ & $3^{\prime} \mathrm{UTR}, \mathrm{CP}$ & Aus16A_SPVC & MF572065_SPVC & $\mathrm{R}, \mathrm{B}, \mathrm{M}, \mathrm{C}, \mathrm{S}$ & $6.699 \times 10^{-09}$ \\
\hline $26^{\mathrm{h}}$ & SPVC & KU511269_C & $6,932-10,825$ & $\begin{array}{l}\text { 3' UTR, NIa-Pro, } \\
\text { NIb, CP }\end{array}$ & KF386015_SPVC & MF572058_SPVC & $\mathrm{R}, \mathrm{B}, \mathrm{M}, \mathrm{C}, \mathrm{S}$ & $8.459 \times 10^{-30}$ \\
\hline $27^{\mathrm{g}}$ & SPFMV_A -EA(I) & FJ155666_Piu3 & $7,708-8,747$ & NIa-Pro & KT069222_SPFMV_A-EA(I) & MF572056_SPFMV_A-O(II) & $\mathrm{R}, \mathrm{G}, \mathrm{B}, \mathrm{M}, \mathrm{C}, \mathrm{S}, \mathrm{T}$ & $3.911 \times 10^{-21}$ \\
\hline $28^{\mathrm{d}}$ & SPFMV_A-O(II) & MF572056_TM66B & $9,634-9,964$ & $\mathrm{NIb}, \mathrm{CP}$ & AB439206_SPFMV_A-O(II) & D86371_SPFMV_B(RC) & $\mathrm{R}, \mathrm{G}, \mathrm{B}, \mathrm{M}, \mathrm{C}, \mathrm{S}$ & $7.976 \times 10^{-23}$ \\
\hline $29^{f}$ & SPVC & Aus16A & $10,664-10,855$ & 3' UTR, CP & Aus15A_SPVC & Aus22D_SPFMV_B(RC) & $\mathrm{G}, \mathrm{B}, \mathrm{S}, \mathrm{T}$ & $7.086 \times 10^{-04}$ \\
\hline $30^{\mathrm{g}}$ & SPFMV_A-EA(I) & KT069222_ZA-O & $7,959-8,747$ & NIa-Pro & KP729265_SPFMV_A-EA(I) & KF386013_SPFMV_A-O(II) & $\mathrm{R}, \mathrm{G}, \mathrm{B}, \mathrm{M}, \mathrm{S}, \mathrm{T}$ & $8.218 \times 10^{-11}$ \\
\hline $31^{\mathrm{h}}$ & SPVC & KU511269_AM-MB2 & $6,354-8,339$ & $6 \mathrm{~K} 2, \mathrm{C} 1$ & KP115621_SPVC & Aus17A_SPVC & $\mathrm{R}, \mathrm{G}, \mathrm{B}, \mathrm{M}, \mathrm{C}, \mathrm{S}, \mathrm{T}$ & $6.364 \times 10^{-11}$ \\
\hline $32^{\mathrm{h}}$ & SPVC & MF572067_TM68A & $6,434-7,234$ & $6 \mathrm{~K} 2, \mathrm{C} 1$ & MF572059_SPVC & MF572063_SPVC & $\mathrm{R}, \mathrm{B}, \mathrm{M}, \mathrm{C}, \mathrm{S}$ & $9.652 \times 10^{-14}$ \\
\hline $33^{\mathrm{h}}$ & SPVC & KU511269_AM-MB2 & $1-1,753$ & $\mathrm{P} 1$ & GU207957_SPVC & MF572060_SPVC & $\mathrm{R}, \mathrm{G}, \mathrm{B}, \mathrm{M}, \mathrm{C}, \mathrm{S}, \mathrm{T}$ & $6.689 \times 10^{-15}$ \\
\hline $34^{\mathrm{h}}$ & SPVC & MF572067_TM68A & $1-2,056$ & $\mathrm{P} 1$ & GU207957_SPVC & KT069223_SPVC & $\mathrm{R}, \mathrm{G}, \mathrm{B}, \mathrm{M}, \mathrm{C}, \mathrm{S}, \mathrm{T}$ & $8.266 \times 10^{-07}$ \\
\hline $35^{\mathrm{h}}$ & SPVC & MF572067_TM68A & $6,911-8,219$ & 6K2, NIb & KF386015_SPVC & Aus17A-SPVC & R,G,B,M,C,S,T & $9.249 \times 10^{-11}$ \\
\hline $36^{\mathrm{g}}$ & SPFMV_A-EA(I) & FJ155666_Piu3 & $8,603-9,448$ & $\mathrm{NIb}$ & MF572055_SPFMV_A-EA(I) & MF572056_SPFMV_A-O(II) & $\mathrm{R}, \mathrm{G}, \mathrm{B}, \mathrm{M}, \mathrm{C}, \mathrm{S}$ & $7.292 \times 10^{-14}$ \\
\hline $37^{\mathrm{d}}$ & SPFMV_A-O(II) & KT069222_ZA-O & $8,412-8,834$ & $\mathrm{NIb}$ & MF572050_SPFMV_A-O(II) & MF572047_SPFMV_B(RC) & $\mathrm{R}, \mathrm{G}, \mathrm{B}, \mathrm{C}$ & $7.036 \times 10^{-06}$ \\
\hline $38^{\mathrm{h}}$ & SPVC & MF572067_TM68A & $8,242-9,882$ & $\mathrm{NIb}$ & MF572063_SPVC & KT069223_SPVC & $\mathrm{R}, \mathrm{B}, \mathrm{M}, \mathrm{C}, \mathrm{S}$ & $4.140 \times 10^{-06}$ \\
\hline $39^{\mathrm{d}}$ & SPFMV_A-EA(I) & KP729265_Ruk73 & $9,748-10,392$ & $\mathrm{CP}$ & MF572050_SPFMV_A-O(II) & MF572051_SPFMV_B(RC) & $\mathrm{R}, \mathrm{B}, \mathrm{M}, \mathrm{C}, \mathrm{T}$ & $6.755 \times 10^{-09}$ \\
\hline $40^{\mathrm{h}}$ & SPVC & KF386015_Arg & $2,257-6,901$ & HC-Pro, NIa-Pro & MF572066_SPVC & MF572057_SPVC & $\mathrm{R}, \mathrm{B}, \mathrm{M}, \mathrm{C}, \mathrm{S}$ & $7.061 \times 10^{-08}$ \\
\hline $41^{\mathrm{f}}$ & SPFMV_B(RC) & Aus 18D & $6,688-6,874$ & $6 \mathrm{~K} 2$ & Aus13D_SPFMV_B(RC) & MF572060_SPVC & $\mathrm{R}, \mathrm{G}, \mathrm{B}, \mathrm{M}$ & $8.485 \times 10^{-09}$ \\
\hline $42^{\mathrm{e}}$ & SPFMV_A-O(II) & Aus15B & $160-354$ & P1 & Aus16B_SPFMV_A-O(II) & MF572060_SPVC & $\mathrm{G}, \mathrm{B}, \mathrm{M}, \mathrm{C}, \mathrm{S}, \mathrm{T}$ & $8.569 \times 10^{-50}$ \\
\hline $43^{f}$ & SPFMV_B(RC) & Aus19D & $6,225-6,378$ & $\mathrm{C} 1$ & Aus18D_SPFMV_B(RC) & MF572061_SPVC & $\mathrm{R}, \mathrm{G}, \mathrm{B}, \mathrm{M}, \mathrm{C}$ & $5.946 \times 10^{-45}$ \\
\hline $44^{g}$ & SPFMV_A-EA(I) & MF572055_TM33C & $8,830-8,870$ & NIa-Pro & KT069222_ZA-O_A-EA(I) & MF572056_SPFMV_A-O(II) & $\mathrm{R}, \mathrm{G}, \mathrm{B}, \mathrm{M}, \mathrm{C}, \mathrm{S}, \mathrm{T}$ & $3.911 \times 10^{-21}$ \\
\hline
\end{tabular}

a There were no SPFMV_B(RC) $\times$ SPFMV_B(RC) intraspecies recombination events. UTR = untranslated region and $\mathrm{CP}=$ coat protein.

b SPFMV phylogroup A's minor phylogroup EA information provided in this table reflects the phylogroups prior to the recombination analysis data provided subsequently, which questions the existence of minor phylogroup A as a distinct grouping. Also, the closest nucleotide identity for KT069222_ZA-O was actually with minor phylogroup $\mathrm{O}$ sequence rather than with any minor phylogroup EA sequences. Parental sequences with isolate names instead of accession numbers are all new ones from this study.

c Abbreviation: 3 = 3Seq, $\mathrm{B}=$ Bootscan, $\mathrm{C}=$ Chimera, $\mathrm{G}=$ GENECONV, $\mathrm{M}=$ MaxChi, $\mathrm{S}=\mathrm{SiScan}$, and $\mathrm{T}=\mathrm{Topal}$.

d SPFMV_A-O(II) (including A-EA(II)) $\times$ SPFMV_B(RC) (intraspecies, between major phylogroups).

e SPFMV_A-O(II) (including A-EA(I)) $\times$ SPVC (interspecies).

${ }^{f}$ SPFMV_B(RC) $\times$ SPVC (interspecies).

g SPFMV_A-O(II) (including (A-EA(I)) × SPFMV_A-O(II) (including (A-EA(I)) (intraspecies, within phylogroup).

${ }^{\mathrm{h}} \mathrm{SPVC} \times$ SPVC (intraspecies). 
et al. 2011; Moury 2010; Ogawa et al. 2012; Santillan et al. 2018; Visser et al. 2012). Furthermore, when few complete genomes are available for a particular virus species, it will often be undesirable to discard an excessive amount of data in the pursuit of recombinationfree datasets. In this study, we prepared phylogenetic trees containing SPFMV genomes with and without recombinant genomes but there were still too few available SPVC genomes to remove recombinants. Therefore, we opted to construct phylogenetic trees containing SPFMV and SPVC sequences from which tracts of recombinationally derived sequences had been removed. Constructing a phylogenetic tree accounting for recombination allowed us to gain an understanding of potential SPVC phylogroups based on complete genomes, and these differed from those based on CP genes reported previously (Maina et al. 2018b). With SPFMV, the phylogenetic tree accounting for recombination revealed subdivision of major phylogroup $\mathrm{B}(\mathrm{RC})$ into two minor phylogroups. Moreover, minor phylogroup $\mathrm{EA}(\mathrm{I})$ disappeared, its five constituent sequences now falling within phylogroup $\mathrm{O}(\mathrm{II})$, in which they failed to form a monophyletic cluster. Also, the closest nucleotide identity for KT069222_ZA-O was actually with the minor phylogroup O sequence rather than with any minor phylogroup EA sequences. This raises the question as to whether phylogroup EA(I) actually exists, or if it should rather be considered as being part of minor phylogroup $\mathrm{O}(\mathrm{I})$.

Australian SPFMV genomes mostly grouped together in major phylogroup $\mathrm{B}(\mathrm{RC})$ but, within minor phylogroup $\mathrm{O}(\mathrm{II})$, four of the Australian genomes grouped closely (up to $97.4 \%$ identity) with TM64B, a sequence from East Timor. Within this minor phylogroup, the single Australian sequence that Maina et al. (2018b) found grouping closely with East Timorese sequence TM64B was Aus13B from the Perth region in southwest Australia, although the three new sequences from this study that grouped closely with TM64B were from Kununurra $(n=2)$ and Cairns $(n=1)$. Kununurra is close to East Timor and is a recipient of the southwesterly monsoonal winds from there; thus, this genetic match might have arisen by windblown aphid vectors bringing the SPFMV across the sea to Australia. This would be consistent with our hypothesis that "important plant viral pathogens of economically important crops are arriving in tropical northern Australia by crossing the sea separating it from neighboring islands to the north". Alternatively, as discussed by Maina et al. (2018a), importation of virus-infected tuberous roots into Australia and East Timor might have occurred from the same external source, or the tuberous roots might have been imported from East Timor to Australia, or vice versa. However, there is no record of any sweetpotato trade between the two countries. SPFMV isolates from Argentina and Japan had nucleotide identities that were $0.2 \%$ closer than the East Timorese sequence TM64B to the nearest Australian sequence within this minor phylogroup O(II). Such a small difference does not detract from the genetic connectivity between East Timorese and Australian sequences but demonstrates that there is genetic connectivity between all of these sequences. With SPVC, the new and all but one of the previous Australian sequences grouped closely together. The closest genetic match between an Australian and a Southeast Asian sequence, which was from East Timor, was more distant than with SPFMV, also resembling the findings of Maina et al. (2018b).

In addition to this study, other investigations have also indicated the widespread occurrence of SPFMV and SPVC in Australian sweetpotato (Jones and Dwyer 2007; Maina et al. 2018b; Tairo et al. 2005, 2006). Collectively these studies suggest that the Australian national sweetpotato pathogen-tested stock program (QLD-GOV 2015) would be well advised to consider implementing more rigorous routine testing procedures than those currently in use. Maina et al. (2018b) emphasized an urgent need to increase not only viral pathogen surveillance activities in northern Australia but also preparedness for the containment and eradication of new virus incursions (Maina et al. 2018b). The finding of partial sequences of CMV and SPVCV in Australian sweetpotato in this study, in addition to several other sweetpotato viruses other than SPFMV and SPVC found in previous studies (Jones and Dwyer 2007; Maina et al. (2016a,b,c, 2018a; Tairo et al. 2005, 2006), reemphasizes the importance of implementing such biosecurity measures to protect the national sweetpotato crop from exotic viruses.

\section{Acknowledgments}

We thank J. Ray and R. Davis of the Northern Australian Quarantine Strategy for supplying the tuberous root samples from Darwin and Cairns, respectively; E. Gajda, M. Banovic, F. Wangari, R. Creasy, and B. Piasini for glasshouse support at the Department of Agriculture and Food Western Australia or the University of Western Australia; and M. You of the School of Agriculture and Environment, UWA for administrative support.

\section{Literature Cited}

Altschul, S. F., Gish, W., Miller, W., Myers, E. W., and Lipman, D. J. 1990. Basic local alignment search tool. J. Mol. Biol. 215:403-410.

Atkey, P. T., and Brunt, A. A. 1987. Electron microscopy of an isometric Caulimolike virus from sweetpotato (Ipomoea batatas). J. Phytopathol. 118:370-376.

Bao, Y., Chetvernin, V., and Tatusova, T. 2014. Improvements to pairwise sequence comparison (PASC): A genome-based web tool for virus classification. Arch. Virol. 159:3293-3304.

Boni, M. F., Posada, D., and Feldman, M. W. 2007. An exact nonparametric method for inferring mosaic structure in sequence triplets. Genetics 176 1035-1047.

Chare, E. R., and Holmes, E. C. 2006. A phylogenetic survey of recombination frequency in plant RNA viruses. Arch. Virol. 151:933-946.

Chikh-Ali, M., Vander Pol, D., Nikolaeva, O. V., Melzer, M. J., and Karasev, A. V. 2016. Biological and molecular characterization of a tomato isolate of Potato virus $Y$ (PVY) of the PVYC lineage. Arch. Virol. 161:3561-3566.

Choi, S. H., Hagiwara-Komoda, Y., Nakahara, K. S., Atsumi, G., Shimada, R., Hisa, Y., Naito, S., and Uyeda, I. 2013. Quantitative and qualitative involvement of $\mathrm{P} 3 \mathrm{~N}-\mathrm{PIPO}$ in overcoming recessive resistance against Clover yellow vein virus in pea carrying the cyv1 gene. J. Virol. 87:7326-7337.

Clark, C. A., Davis, J. A., Abad, J. A., Cuellar, W. J., Fuentes, S., Kreuze, J. F., Gibson, R. W., Mukasa, S. B., Tugume, A. K., Tairo, F. D., and Valkonen, J. P. 2012. Sweetpotato viruses: 15 years of progress on understanding and managing complex diseases. Plant Dis. 96:168-185.

Coleman, E. A., Hughes, M. J., Jackson, G. V., Komolong, B., and Guaf, E. 2009. Genetics and disease as factors in the yield decline of sweetpotato in the Papua New Guinea highlands. Pages 33-42 in: Soil Fertility in Sweetpotato-Based Cropping Systems in the Highlands of Papua New Guinea. G. Kirchoff, ed. Australian Centre for International Agricultural Research, Canberra, Australia.

Coutts, B. A., Kehoe, M. A., Webster, C. G., Wylie, S. J., and Jones, R. A. C. 2011 Zucchini yellow mosaic virus: Biological properties, detection procedures and comparison of coat protein gene sequences. Arch. Virol. 156:2119-2131.

Cuevas, J. M., Delaunay, A., Visser, J. C., Bellstedt, D. U., Jacquot, E., and Elena, S. F. 2012. Phylogeography and molecular evolution of Potato virus Y. PLoS One $7:$ e37853

Denham, T., Haberle, S., and Lentfer, C. 2004. New evidence and revised interpretations of early agriculture in highland New Guinea. Antiquity 78:839-857.

Desbiez, C., and Lecoq, H. 2008. Evidence for multiple intraspecific recombinants in natural populations of Watermelon mosaic virus (WMV, Potyvirus). Arch Virol. 153:1749-1754.

Eagles, D., Walker, P. J., Zalucki, M. P., and Durr, P. A. 2013. Modelling spatiotemporal patterns of long-distance Culicoides dispersal into northern Australia. Prev. Vet. Med. 110:312-322.

Edgar, R. C. 2004. MUSCLE: A multiple sequence alignment method with reduced time and space complexity. BMC Bioinf. 5:113.

EPPO. 2014. Plant Quarantine Database. European and Mediterranean Plant Protection Organization, Paris. http://www.eppo.int/DATABASES/pqr/pqr.htm

FAOSTAT. 2017. Food and agriculture data. Food and Agriculture Organization of the United Nations, Rome. http://www.fao.org/faostat/en/\#data

Gibbs, A. J., Mackenzie, A., Wei, K., and Gibbs, M. J. 2008. The potyviruses of Australia. Arch. Virol. 153:1411-1420.

Gibbs, A. J., and Ohshima, K. 2010. Potyviruses and the digital revolution. Annu. Rev. Phytopathol. 48:205-223.

Gibbs, A. J., Ohshima, K., Yasaka, R., Mohammadi, M., Gibbs, M. J., and Jones, R. A. C., 2017. The phylogenetics of the global population of Potato virus $Y$ and its necrogenic recombinants. Virus Evol. 3:vex002.

Gibbs, M. J., Armstrong, J. S., and Gibbs, A. J. 2000. Sister-scanning: A Monte Carlo procedure for assessing signals in recombinant sequences. Bioinformatics 16:573-582.

Guerret, M. G. L., Nyalugwe, E. P., Maina, S., Barbetti, M. J., van Leur, J. A. G., and Jones, R. A. C. 2017. Biological and molecular properties of a Turnip mosaic virus (TuMV) strain that breaks TuMV resistances in Brassica napus. Plant Dis. 101:674-683.

Ha, C., Revill, P., Harding, R. M., Vu, M., and Dale, J. L. 2008. Identification and sequence analysis of potyviruses infecting crops in Vietnam. Arch. Virol. 153: 45-60.

Hutterer, K. P. 1983. The natural and cultural history of Southeast Asian agriculture: Ecological and evolutionary considerations. Anthropos 78:169-212. 
James, D., Sanderson, D., Varga, A., Sheveleva, A., and Chirkov, S. 2016. Genome sequence analysis of new isolates of the Winona strain of Plum pox virus and the first definitive evidence of intrastrain recombination events. Phytopathology 106:407-416.

Jones, R. A. C. 2009. Plant virus emergence and evolution: Origins, new encounter scenarios, factors driving emergence, effects of changing world conditions, and prospects for control. Virus Res. 141:113-130.

Jones, R. A. C., and Dwyer, D. I. 2007. Detection of Sweetpotato chlorotic fleck virus and Sweetpotato feathery mottle virus-strain $\mathrm{O}$ in Australia. Australas. Plant Pathol. 36:591-594.

Jones, R. A. C., and Kehoe, M. A. 2016. A proposal to rationalize within-species plant virus nomenclature: Benefits and implications of inaction. Arch. Virol. 161:2051-2057.

Karasev, A. V., Hu, X., Brown, C. J., Kerlan, C., Nikolaeva, O. V., Crosslin, J. M., and Gray, S. M. 2011. Genetic diversity of the ordinary strain of Potato virus $Y$ (PVY) and origin of recombinant PVY strains. Phytopathology 101:778-785.

Karyeija, R. F., Gibson, R. W., and Valkonen, J. P. T. 1998. The significance of Sweetpotato feathery mottle virus in subsistence sweetpotato production in Africa. Plant Dis. 82:4-15.

Kashif, M., Pietilä, S., Artola, K., Jones, R. A. C., Tugume, A. K., Mäkinen, V., and Valkonen, J. P. T. 2012. Detection of viruses in sweetpotato from Honduras and Guatemala augmented by deep-sequencing of small-RNAs. Plant Dis. 96:1430-1437.

Katoh, K., Misawa, K., Kuma, K.-I., and Miyata, T. 2002. MAFFT: A novel method for rapid multiple sequence alignment based on fast Fourier transform. Nucleic Acids Res. 30:3059-3066.

Kays, S., Wang, Y., and McLaurin, W. 2005. Chemical and geographical assessment of the sweetness of the cultivated sweetpotato clones of the world. J. Am. Soc. Hortic. Sci. 130:591-597.

Kearse, M., Moir, R., Wilson, A., Stones-Havas, S., Cheung, M., Sturrock, S., Buxton, S., Cooper, A., Markowitz, S., Duran, C., Thierer, T., Ashton, B., Meintjes, P., and Drummond, A. 2012. Geneious Basic: An integrated and extendable desktop software platform for the organization and analysis of sequence data. Bioinformatics 28:1647-1649.

Kehoe, M. A., Coutts, B. A., Buirchell, B., and Jones, R. A. C. 2014a. Plant virology and next generation sequencing: Experiences with a Potyvirus. PLoS One 9:e104580.

Kehoe, M. A., Coutts, B. A., Buirchell, B., and Jones, R. A. C. 2014b. Split personality of a potyvirus: To specialize or not to specialize. PLoS ONE 9:e105770.

Kreuze, J. F., Karyeija, R. F., Gibson, R. W., and Valkonen, J. P. T. 2000. Comparisons of coat protein gene sequences show that East African isolates of Sweet potato feathery mottle virus form a genetically distinct group. Arch. Virol. 145:567-574.

Kumar, S., Stecher, G., and Tamura, K. 2016. MEGA7: Molecular evolutionary genetics analysis version 7.0 for bigger datasets. Mol. Biol. Evol. 33: 1870-1874.

Kwak, H. R., Kim, J., Kim, M. K., Seo, J. K., Jung, M. N., Kim, J. S., Lee, S., and Choi, H. S. 2015. Molecular characterization of five potyviruses infecting Korean sweet potatoes based on analyses of complete genome sequences. Plant Pathol. J. 31:388-401.

Lai, M. M. 1992. RNA recombination in animal and plant viruses. Microbiol. Rev. 56:61-79.

Larkin, M. A., Blackshields, G., Brown, N. P., Chenna, R., McGettigan, P. A., McWilliam, H., Valentin, F., Wallace, I. M., Wilm, A., Lopez, R., and Thompson, J. D. 2007. Clustal W and Clustal X version 2.0. Bioinformatics 23:2947-2948

Loebenstein, G., Thottappilly, G., Fuentes, S. and Cohen, J. 2009. Virus and phytoplasma diseases. Pages 105-134 in: The Sweetpotato. G. Loebenstein and G. Thottappilly, eds. Springer, The Netherlands.

Maina, S., Barbetti, M. J., Edwards, O. R., Minemba, D., Areke, M. W., and Jones, R. A. C. 2018a. First complete Cucurbit aphid-borne yellows virus genome from Papua New Guinea. Genome Announc. 6:e00162-18.

Maina, S., Coutts, B. A., Edwards, O. R., de Almeida, L., Kehoe, M. A., Ximenes, A., and Jones, R. A. C. 2017a. Zucchini yellow mosaic virus populations from East Timorese and northern Australian cucurbit crops: Molecular properties, genetic connectivity and biosecurity implications. Plant Dis. 101: 1236-1245.

Maina, S., Coutts, B. A., Edwards, O. R., de Almeida, L., Ximenes, A., and Jones, R. A. C. 2017b. Papaya ringspot virus populations from East Timorese and northern Australian cucurbit crops: Biological and molecular properties, and absence of genetic connectivity. Plant Dis. 101:985-993.

Maina, S., Edwards, O. R., Barbetti, M. J., de Almeida, L., Ximenes, A., and Jones, R. A. C. 2016a. Deep sequencing reveals complete genome of Sweetpotato virus $G$ from East Timor. Genome Announc. 4:e00957-e16.

Maina, S., Edwards, O. R., Barbetti, M. J., de Almeida, L., Ximenes, A., and Jones, R. A. C. 2018b. Sweet potato feathery mottle virus and Sweet potato virus $C$ from East Timorese and Australian sweetpotato; Biological and molecular properties, and biosecurity implications. Plant Dis. 102:589-599.

Maina, S., Edwards, O. R., de Almeida, L., Ximenes, A., and Jones, R. A. C. 2016b. Complete genome sequences of the Carlavirus Sweetpotato chlorotic fleck virus from East Timor and Australia. Genome Announc. 4: e00414-e16.
Maina, S., Edwards, O. R., de Almeida, L., Ximenes, A., and Jones, R. A. C. 2016c. Complete genome sequences of the Potyvirus Sweetpotato virus 2 from East Timor and Australia. Genome Announc. 4:e00504-e16.

Maina, S., Edwards, O. R., de Almeida, L., Ximenes, A., and Jones, R. A. C. 2016d. First complete genome sequence of Suakwa aphid-borne yellows virus from East Timor. Genome Announc. 4:e00718-e16.

Maina, S., Edwards, O. R., de Almeida, L., Ximenes, A., and Jones, R. A. C. 2016e. First complete genome sequence of Bean common mosaic necrosis virus from East Timor. Genome Announc. 4:e01049-e16.

Maina, S., Edwards, O. R., de Almeida, L., Ximenes, A., and Jones, R. A. C. 2017c. Metagenomic analysis of cucumber RNA from East Timor reveals an Aphid lethal paralysis virus genome. Genome Announc. 5:e01445-e16.

Maina, S., Edwards, O. R., de Almeida, L., Ximenes, A., and Jones, R. A. C. 2017d. RNA-seq strand specific library from East Timorese cucumber sample reveals complete Cucurbit aphid-borne yellows virus genome. Genome Announc. 5:e00320-e17.

Maina, S., Edwards, O. R., de Almeida, L., Ximenes, A., and Jones, R. A. C. 2017e. First complete Squash leaf curl China virus genomic segment DNAA sequence from East Timor. Genome Announc. 5:e00483-e17.

Maina, S., Edwards, O. R., and Jones, R. A. C. 2016f. First complete genome sequence of Pepper vein yellows virus from Australia. Genome Announc. 4: e00450-e16.

Maina, S., Edwards, O. R., and Jones, R. A. C. 2017f. Two complete genome sequences of Squash mosaic virus from 20-year-old cucurbit leaf samples from Australia. Genome Announc. 5:e00778-e17.

Maina, S., and Jones, R. A. C. 2017. Analysis of an RNA-seq strand-specific library sample reveals a complete genome of Hardenbergia mosaic virus from native wisteria, an indigenous virus from Southwest Australia. Genome Announc. 5:e00599-17.

Martin, D. P., Murrell, B., Golden, M., Khoosal, A., and Muhire, B. 2015. RDP4 Detection and analysis of recombination patterns in virus genomes. Virus Evol. 1:vev003.

Martin, D. P., Williamson, C., and Posada, D. 2005. RDP2: Recombination detection and analysis from sequence alignment. Bioinformatics 21:260-262.

Moury, B. 2010. A new lineage sheds light on the evolutionary history of Potato virus Y. Mol. Plant Pathol. 11:161-168.

Moyer, J. W., Cali, B. B., Kennedy, G. G., and Abu-Ghadir, M. F. 1980 Identification of sweetpotato feathery mottle virus strains in North Carolina. Plant Dis. 64:762-764.

Moyer, J. W., and Salazar, L. F. 1989. Viruses and virus like diseases of sweetpotato. Plant Dis. 73:451-455.

Muhire, B. M., Varsani, A., and Martin, D. P. 2014. SDT: A virus classification tool based on pairwise sequence alignment and identity calculation. PLoS One 9:e108277.

Mukasa, S. B., Tairo, F., Kullaya, A., Rubaihayo, P. R., and Valkonen, J. P. T. 2003. Coat protein sequence analysis reveals occurrence of new strains of Sweetpotato feathery mottle virus in Uganda and Tanzania. Virus Genes 27:49-56.

Myrta, A., Boscia, D., Potere, O., Kölber, M., Németh, M., Di Terlizzi, B., Cambra, M., and Savino, V. 2001. Existence of two serological subclusters of Plum pox virus, strain M. Eur. J. Plant Pathol. 107:845-848.

Ogawa, T., Nakagawa, A., Hataya, T., and Ohshima, K. 2012. The genetic structure of populations of Potato virus $Y$ in Japan; based on the analysis of 20 full genomic sequences. J. Phytopathol. 160:661-673.

Ohshima, K., Tomitaka, Y., Wood, J. T., Minematsu, Y., Kajiyama, H., Tomimura, K., and Gibbs, A. J. 2007. Patterns of recombination in Turnip mosaic virus genomic sequences indicate hotspots of recombination. J. Gen. Virol. 88:298-315.

Ohshima, K., Yamaguchi, Y., Hirota, R., Hamamoto, T., Tomimura, K., Tan, Z. Sano, T., Azuhata, F., Walsh, J. A., Fletcher, J., Chen, J., Gera, A., and Gibbs, A. 2002. Molecular evolution of Turnip mosaic virus: Evidence of host adaptation, genetic recombination and geographical spread. J. Gen. Virol. 83: 1511-1521.

Padidam, M., Sawyer, S., and Fauquet, C. M. 1999. Possible emergence of new geminiviruses by frequent recombination. Virology 265:218-225.

Posada, D., and Crandall, K. A. 2001. Evaluation of methods for detecting recombination from DNA sequences: Computer simulations. Proc. Natl. Acad. Sci. USA 98:13757-13762.

Prain, G., Machmud, M., and Rusmadi. 1998. Evaluation of virus diseases. Annual subproject progress report 080304 for Indonesia. International Potato Center, Lima, Peru.

Purnomo, B. W. 2003. Sweetpotato feathery mottle virus (SPFMV) elimination of four sweetpotato local superior varieties of Papua origin by using meristem culture. Indonesian. J. Agron. 31:81-88.

QLD-GOV. 2015. Producing Pathogen-tested Sweetpotato Planting Material. Department of Agriculture and Fisheries, Queensland Government, Brisbane, Australia. https://www.daf.qld.gov.au/business-priorities/plants/fruit-andvegetables/vegetables/sweetpotato/pathogen-tested-planting-material; https:// www.daf.qld.gov.au/plants/fruit-and-vegetables/vegetables/sweetpotato/pathogentested-planting-material

Rännäli, M., Czekaj, V., Jones, R. A. C., Fletcher, J. D., Mu, L., Davis, R. I., and Valkonen, J. P. T. 2009. Molecular characterization of Sweetpotato feathery mottle virus (SPFMV) isolates from Easter Island, French Polynesia, New Zealand and southern Africa. Plant Dis. 93:933-939. 
Revers, F., Le Gall, O., Candresse, T., Le Romancer, M., and Dunez, J. 1996. Frequent occurrence of recombinant potyvirus isolates. J. Gen. Virol. 77:1953-1965.

Salminen, M. 2003. Detecting recombination in viral sequences. Pages 348-377 in: The Phylogenetic Handbook-A Practical Approach to DNA and Protein Phylogeny. M. Salemi and A.-M. Vandamme, eds. Cambridge University Press, Cambridge, United Kingdom.

Santillan, F., Fribourg, C., Adams, I., Gibbs, A. J., Boonham, N., Kehoe, M., Maina, S., and Jones, R. A. C. 2018. The biology and phylogenetics of Potato virus $S$ isolates from the Andean region of South America. Plant Dis. 102:869-885.

Smith, J. M. 1992. Analyzing the mosaic structure of genes. J. Mol. Evol. 34:126-129.

Tairo, F., Jones, R. A. C., and Valkonen, J. P. T. 2006. Potyvirus complexes in sweetpotato: Occurrence in Australia, serological and molecular resolution, and analysis of the Sweetpotato virus 2 (SPV2) component. Plant Dis. 90:1120-1128.

Tairo, F., Mukasa, S. B., Jones, R. A. C., Kullaya, A., Rubaihayo, P. R., and Valkonen, J. P. T. 2005. Unravelling the genetic diversity of the three main viruses involved in Sweet Potato Virus Disease (SPVD) and its practical implications. Mol. Plant Pathol. 6:199-211.

Tan, Z., Wada, Y., Chen, J., and Ohshima, K. 2004. Inter- and intra-lineage recombinants are common in natural populations of Turnip mosaic virus. J. Gen. Virol. 85:2683-2696.

Tugume, A. K., Mukasa, S. B., Kalkinen, N., and Valkonen, J. P. T. 2010. Recombination and selection pressure in the ipomovirus Sweet potato mild mottle virus (Potyviridae) in wild species and cultivated sweetpotato in the centre of evolution in East Africa. J. Gen. Virol. 91:1092-1108.

Untiveros, M., Fuentes, S., and Kreuze, J. 2008. Molecular variability of Sweetpotato feathery mottle virus and other potyviruses infecting sweetpotato in Peru. Arch. Virol. 153:473-483.
Untiveros, M., Quispe, D., and Kreuze, J. 2010. Analysis of complete genomic sequences of isolates of the Sweet potato feathery mottle virus strains C and EA: Molecular evidence for two distinct potyvirus species and two P1 protein domains. Arch. Virol. 155:2059-2063.

Urcuqui-Inchima, S., Haenni, A.-L., and Bernardi, F. 2001. Potyvirus proteins: A wealth of functions. Virus Res. 74:157-175.

Valli, A., Lopez-Moya, J. J., and Garcia, J. A. 2007. Recombination and gene duplication in the evolutionary diversification of P1 proteins in the family Potyviridae. J. Gen. Virol. 88:1016-1028.

Valverde, R. A., Clark, C. A., and Valkonen, J. P. T. 2007. Viruses and virus disease complexes of sweet potato. Plant Viruses 1:116-126.

Valverde, R. A., Lozano, G., Navas-Castillo, J., Ramos, A., and Valdés, F. 2004. First report of Sweet potato chlorotic stunt virus and Sweet potato feathery mottle virus infecting sweet potato in Spain. Plant Dis. $88: 428$.

Visser, J. C., Bellstedt, D. U., and Pirie, M. D. 2012. The recent recombinant evolution of a major crop pathogen Potato virus Y. PLoS One 7:e50631.

Webster, C. G. 2008. Characterisation of Hardenbergia mosaic virus and development of microarrays for detecting viruses in plants. Ph.D. thesis, Murdoch University.

Wen, R. H., and Hajimorad, M. R. 2010. Mutational analysis of the putative pipo of Soybean mosaic virus suggests disruption of PIPO protein impedes movement. Virol. 400:1-7.

Yamasaki, S., Sakai, J., Fuji, S., Kamisoyama, S., Emoto, K., Ohshima, K., and Hanada, K. 2010. Comparisons among isolates of Sweet potato feathery mottle virus using complete genomic RNA sequences. Arch. Virol. 155: $795-800$ 